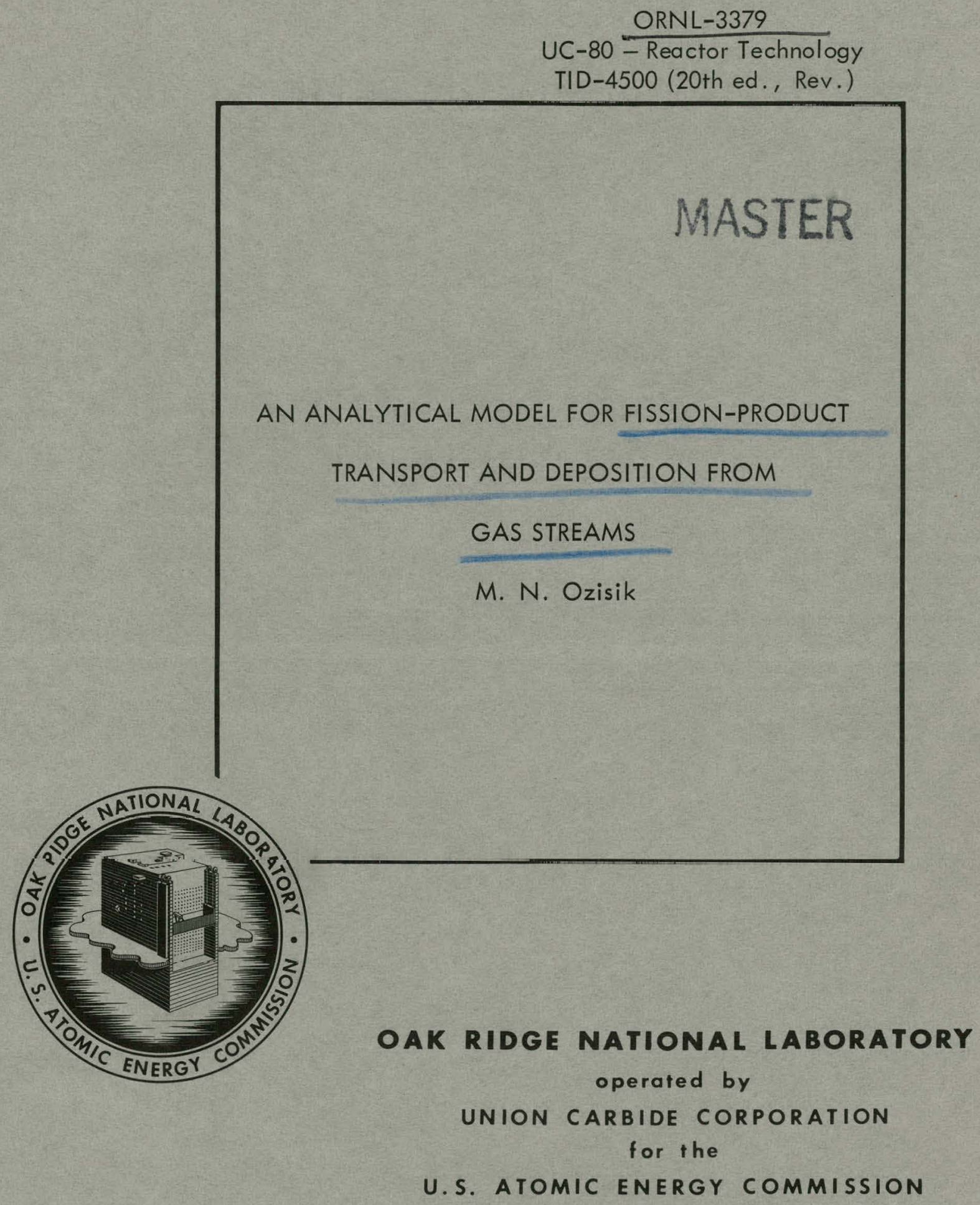




\section{DISCLAIMER}

This report was prepared as an account of work sponsored by an agency of the United States Government. Neither the United States Government nor any agency Thereof, nor any of their employees, makes any warranty, express or implied, or assumes any legal liability or responsibility for the accuracy, completeness, or usefulness of any information, apparatus, product, or process disclosed, or represents that its use would not infringe privately owned rights. Reference herein to any specific commercial product, process, or service by trade name, trademark, manufacturer, or otherwise does not necessarily constitute or imply its endorsement, recommendation, or favoring by the United States Government or any agency thereof. The views and opinions of authors expressed herein do not necessarily state or reflect those of the United States Government or any agency thereof. 


\section{DISCLAIMER}

Portions of this document may be illegible in electronic image products. Images are produced from the best available original document. 


\section{Printed in USA. Price: $\$ 1.25$ Available from the}

Office of Technical Services

U. S. Department of Commerce

Washington 25, D. C.

\section{LEGAL NOTICE}

This report was prepared as an account of Government sponsored work. Neither the United States, nor the Commission, nor any person acting on behalf of the Commission:

A. Makes any warranty or representation, expressed or implied, with respect to the accuracy, completeness, or usefulness of the information contained in this report, or that the use of any information, apparatus, method, or process disclosed in this report may not infringe privately owned rights; or

B. Assumes any liabilities with respect to the use of, or for damages resulting from the use of any information, apparatus, method, or process disclosed in this report.

As used in the above, "person acting on behalf of the Commission" includes any employee or contractor of the Commission, or employee of such contractor, to the extent that such employee or contractor of the Commission, or emplayee of such contractor prepares, disseminates, or provides access to, any information pursuant to his employment or contract with the Commission, or his employment with such contractor. 
Contract No. W-7405-eng-26

Reactor Division

AN ANALYTICAL MODEL FOR FISSION-PRODUCT TRANSPORT AND DEPOSITION FROM GAS STREAMS

M. N. Ozisik

Date Issued

Q46 - 9969

OAK RIDGE NATIONAL LABORATORY

Dak Ridge, Tennessee

operated by

UNION CARBIDE CORPORATION

for the

U. S. ATOMIC ENERGY COMMISSION 
THIS PAGE

\section{WAS INTENTIONALLY \\ LEFT BLANK}


CONTENTS

Page

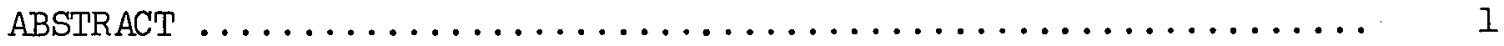

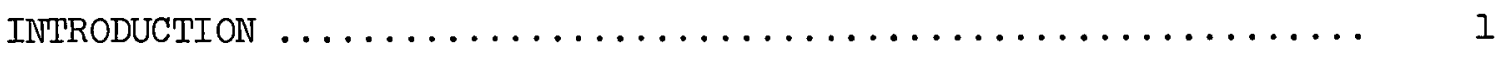

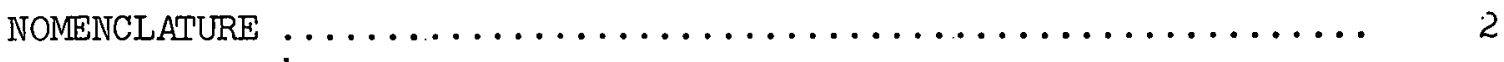

1. MECHANISM OF DEPOSITION $\ldots \ldots \ldots \ldots \ldots \ldots \ldots \ldots \ldots \ldots \ldots \ldots \ldots \ldots \ldots \ldots \ldots$

2. EFFECTS OF RADIOACTIVE DECAY ON HEAT-MASS ANALOGY ........ 6

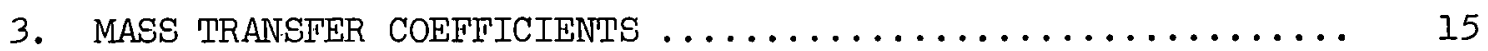

4. ANALYSIS OF FISSION-PRODUCT DEPOSITION RATE WITH THE MASS TRANSFER COEFFICIENT INDEPENDENT OF DISTANCE ........... 17

5. DEPOSTTTON OF DAUG.HTERS OF THE NOBLE GASES $\ldots \ldots \ldots \ldots \ldots \ldots \ldots$

6. DEPOSITION RATE NEAR THE ENTRANCE ................ 25

7. EFFECTS OF CLOSED LOOP ON DEPOSITION RATT ............ 28

8. EFFECTS OF TEMPERATURE GRADIENT ON DEPOSITION RATE ....... 32

9. APPLICATION TO CORRELATION OF EXPERIMENTAL DATA ........ 35

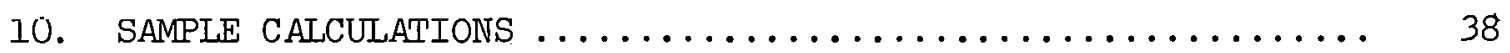

ACKNOWLEDGMENTS $\ldots \ldots \ldots \ldots \ldots \ldots \ldots \ldots \ldots \ldots \ldots \ldots \ldots \ldots \ldots \ldots \ldots \ldots \ldots$

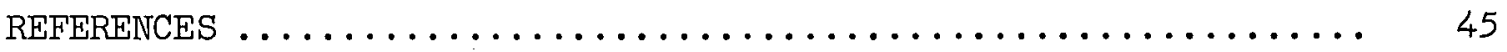




\title{
AN ANALYTICAL MODEL FOR FISSION-PRODUCT TRANSPORT AND DEPOSITION FROM GAS STREAMS
}

M. N. Ozisik

\begin{abstract}
$\underline{\text { Abstract }}$
An important mechanism in the transport and deposition of very small particles from gas streams to the surfaces of a conduit is diffusion due to the Brownian movement of particles. The heat-mass arialogy' is uscd to deccribe the diffusion, and equations are derived for the deposition of fission products from a gas stream to wall surfaces as a function of the distance along the conduit. Effects of radioactive decay on the validity of the heat-mass analogy in applying standard heat transfer relations to predict material transfer to wall surfaces are discussed.
\end{abstract}

\section{INTRODUCTION}

The proposed use of unclad fuel elements in high-temperature gascooled reactors has created the need for investigating the et'tects of fission-product release into the coolant. The fission products released into the coolant will circulate with the stream until they are deposited on the walls of the conduit if they cannot be removed from the stream by some other process. Knowledge of the amount of activity that will be deposited on the walls of the coolant passages is important in shielding calculations and in maintenance planning. The fission products released from a fission source and entering the gas stream will include noble gases, halides, and fine solid particles. These fission products, excluding the noble gases, will deposit on the walls of the conduit. Noble gases will not deposit because of their inertnese, but their daughter products will. A large portion of the fission products will enter the gas stream in molecular or very smail sizes, and they will remain small unless the particles agglomerate. If there are larger size carrier particles in the gas stream, the smaller particles may deposit on them, 
and the motion of a smaller particle deposited on a larger one will be controlled by the motion of the carrier particle. It is believed that carrier particles will exist in the gas stream, but no statement can be made and substantiated by experimental evidence as to the size spectrum of the carrier particles. Since the best available filters can remove particles from the gas stream that are larger than about $0.3 \mu$, the maximum size of carrier particles in a well-filtered stream can be bracketed.

For particles smaller than about 0. $3 \mu$, diffusion due to Brownian or random motion plays an important part in deposition. In the present study the size of particles in the gas stream is assumed to be so small that the principal mechanism for deposition is diffusion due to the random motion of particles. Only particles of uniform sizes are considered. The heat-mass analogy is used to describe diffusion under steady-state conditions. The analytical relations derived may be used for correlating experiments on the deposition of fission products from well-filtered streams to the walls of a conduit.

\section{NOMENCLATURE}

\begin{tabular}{|c|c|}
\hline A & Cross-sectional area for flow, $\mathrm{cm}^{2}$ \\
\hline a & Deposition surface per unit length of conduit, $\mathrm{cm}^{2} / \mathrm{cm}$ \\
\hline $\begin{array}{l}c \\
C_{p}\end{array}$ & $\begin{array}{l}h_{m} x^{r} \text {, as defined by Eqs. }(3.7),(4.1) \text {, and }(6.1) \\
\text { Specific heat, cal } / g \cdot{ }^{\circ} \mathrm{C}\end{array}$ \\
\hline $\mathrm{D}$ & Diffusion coefficient, $\mathrm{cm}^{2} / \mathrm{sec}$ \\
\hline$d_{e}$ & Equivalent passage diameter, $\mathrm{cm}$ \\
\hline d & Inside diameter of tube, $\mathrm{cm}$ \\
\hline$f(x)$ & $\frac{1}{-}\left(\lambda+\frac{4 P C}{\lambda} \frac{1}{x^{r}}\right)$ \\
\hline$F(x)$ & $1\left[\begin{array}{ll}4 \mathrm{PC} & 1 \\
- & 1+4\end{array}\right]$ \\
\hline & $U\left[\begin{array}{ll}u & \left.(I-r) d_{e} x^{r}\right]\end{array}\right.$ \\
\hline
\end{tabular}




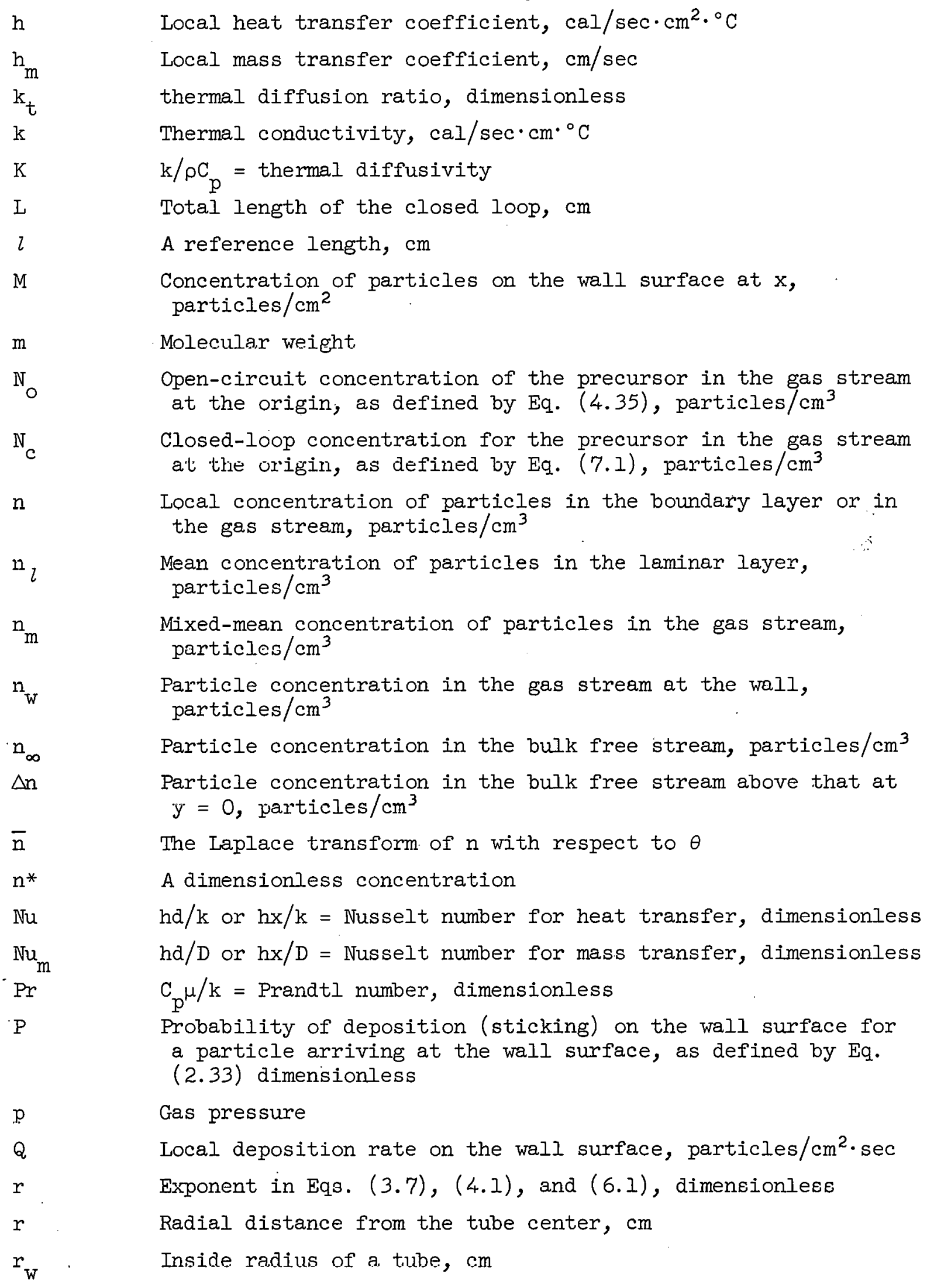




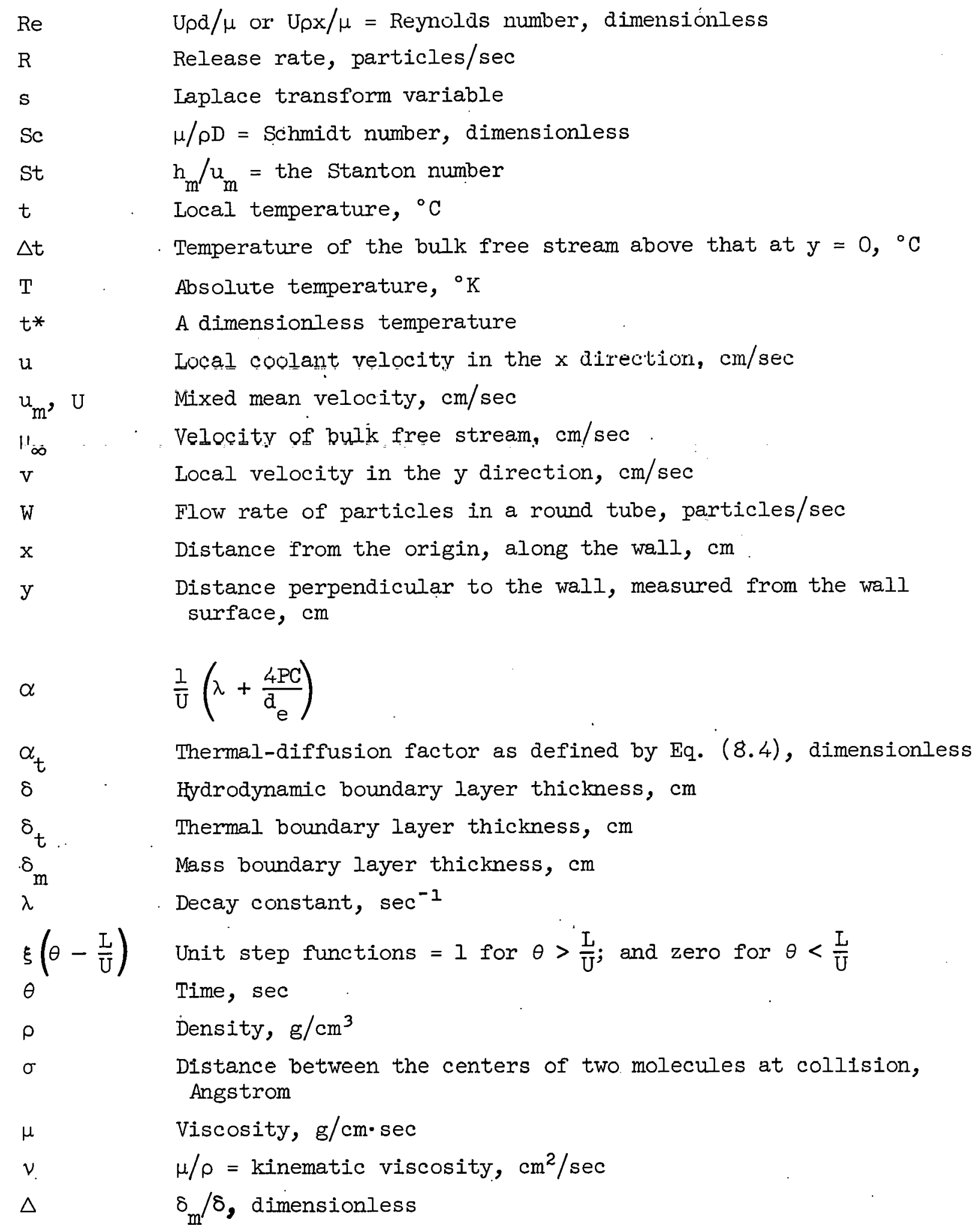




$\begin{array}{ll}\text { Subscripts } & \\ 0 & \text { Precursor } \\ 1 & \text { First daughter product } \\ 2 & \text { Second daughter product } \\ \infty & \text { Edge of boundary layer or bulk free stream } \\ l & \text { Laminar boundary layer } \\ \mathrm{g} & \text { Gas } \\ \text { W } & \text { Wall surface }\end{array}$

\section{MECHANISM OF DEPOSITION}

The fission products or aerosols suspended in a gas stream are uniformly distributed in the turbulent flow region where there is much mixing and eddying. A laminar layer separates the wall surface from the; turbulent core if the surface roughness is small compared with the thickness of the laminar layer. The particles suspended in the gas stream penetrate the laminar layer and reach the wall surface as a result of the dif'fusional, gravitational, inertial, electrostatic, and thermal forces acting on them. The particle size is an important factor affecting the relative magnitude of these forces.

Particles in the gas stream are subject to the inertial effect of eddies. A particle near the laminar layer may penetrate it and reach the wall surface because of the inertia imparted to it by the eddies moving toward the wall. The gravitational, thermal, and electrostatic forces acting on the particles may also causc thcm to pcnetrate the laminar layer and reach the wall surface. In the absence of electric charges and temperature gradients, no electrostatic and thermal forces act on the particles. The effect of gravitational forces on the movement of particles is small compared with diffusional forces for particles smaller than about $0.1 \mu .^{1}$ The inertial effect of eddies is also negligible for such small particles. Hence the principal mechanism for the transport of very small particles across the laminar layer is diffusion due to the Brownian movement of the particles. If the particles arriving at the wall surface are deposited, a concentration gradient is set up 
across the laminar layer, and this concentration gradient becomes the driving potential for the flow of particles toward the wall surface. The process is similar to heat transfer in that diffusion is the principal mechanism of transport in both cases; the concentration gradient replaces the temperature gradient in the mass transfer problem. If the governing equations, geometry, and boundary conditions were similar for the heat and mass transfer problems, a mass transfer coefficient could be obtained from the heat transfer coefficient by analogy, and the mass fluxes could be evaluated. The validity of the standard heat-mass analogy as appliedto the transport and deposition of f1ssion products is in question because the fission products are subject to radioactive decay, whereas no such phenomenon is considered in heat transfer problems. Furthermore, the wall surface is assumed to be a perfect sink for the heat flow, but the fission products arriving at the wall surface may not all deposit on it, that is, the wall surface is not a perfect sink for fission-product deposition. The effects of these differences on the validity of the standard heat-mass analogy for the deposition of fission products from the streams are discussed in the next section.

\section{EFFECTS OF RADIOACTIVE DECAY ON HEAT-MASS ANALOGY}

If an incompressible fluid flowing in the $x$ direction along a flat plate under steady-state forced-flow conditions is assumed, the continuity and momentum equations for the laminar boundary layer with the boundary layer simplifications are, ${ }^{2}$ respectively,

$$
\begin{gathered}
\frac{\partial u}{\partial x}+\frac{\partial v}{\partial y}=0 \\
u \frac{\partial u}{\partial x}+v \frac{\partial u}{\partial y}=v \frac{\partial^{2} u}{\partial y^{2}}
\end{gathered}
$$

The equation for the conservation of particles, or mass balance, in the laminar boundary layer, neglecting diffusion along the $x$ direction (i.e., $\left.D \frac{\partial^{2} n}{\partial x^{2}}\right)$, is 


$$
u \frac{\partial n}{\partial x}+v \frac{\partial n}{\partial y}=D \frac{\partial^{2} n}{\partial y^{2}}-\lambda n
$$

In Eqs. (2.1) through (2.3) the terms bare the following meanings:

$\mathrm{D}=$ diffusion coefficient,

$\mathrm{n}=$ the local concentration of particles in the boundary layer,

$\mathrm{u}=$ local velocity in the $\mathrm{x}$ direction in the boundary layer,

$\mathrm{v}=$ local velocity in the $\mathrm{y}$ direction in the boundary layer,

$y=$ distance from the wall surface (normal to the wall),

$x=$ distance along the wall surface,

$\nu \doteq \mu / \rho=$ kinematic viscosity.

The energy balance equation, excluding the effects of viscous dissipation and conduction along the $\mathrm{x}$ axis, is

$$
u \frac{\partial t}{\partial x}+v \frac{\partial t}{\partial y}=K \frac{\partial^{2} t}{\partial y^{2}}
$$

where

$\mathrm{K}=\mathrm{k} / \mathrm{\rho C}_{\mathrm{p}}=$ thermal diffusivity,

$t_{t}=$ local temperature in the boundary layer.

Note that Eqs. (2.1) and (2.2) are coupled equations from which the velocity distribution can be determined. Substituting these velocities in Eqs. (2.3) and (2.4) give the equations for the particle concentration and temperature distribution in the laminar gas stream. The normal gradients of temperature and particle concentration on the wall surface, to which the heat and mass fluxes are proportional, can be obtained from the solution of these equations. In practice local heat and mass transfer coefficients are introduced for determining the heat and mass fluxes in the direction toward the wall as follows:

$$
\begin{aligned}
& \text { Heat flux }=k\left(\frac{\partial t}{\partial y}\right)_{y=0}=h \Delta t, \\
& \text { Mass flux }=D\left(\frac{\partial n}{\partial y}\right)_{y=0}=h_{m} \Delta n,
\end{aligned}
$$


where

$$
\mathrm{h}=\text { local heat transfer coefficient, }
$$$$
h_{m}=\text { local mass transfer coefficient, }
$$

$\Delta n=$ particle concentration in the bulk free stream above that at $\mathrm{y}=0$,

$\Delta t=$ temperature of the bulk free stream above that at $y=0$.

Equations (2.5) and (2.6) can be put into dimensionless form by introducing a reference length, $l$, as follows:

$$
\begin{gathered}
\mathrm{Nu}=\frac{\mathrm{h} l}{\mathrm{k}}-\left(\frac{\partial \mathrm{t}^{*}}{\partial \mathrm{y}^{*}}\right)_{\mathrm{y}=0}, \\
\mathrm{Nu} \mathrm{m}_{\mathrm{m}} \equiv \frac{\mathrm{h}_{\mathrm{m}} l}{\mathrm{D}}=\left(\frac{\partial \mathrm{h}^{*}}{\partial \mathrm{y}^{*}}\right)_{\mathrm{y}=0},
\end{gathered}
$$

where the quantities marked with the asterisk are dimensionless, that is, $\mathrm{y}^{*}=\mathrm{y} / \mathrm{l}$ and $\mathrm{n}^{*}=\mathrm{n} / \Delta \mathrm{n}$.

Similarly, by introducing a reference velocity, $U$, it can be shown from Eqs. (2.3) and (2.4) that the dimensionless temperature is a function of the Reynolds and the Prandtl number, and the dimensionless concentration is a function of the Reynolds, the Schmidt number, and the quantity $l \lambda / U$. Hence, the general solution of the dimensionless heat and mass transfer coefficients may be expressed in the functional form as

$$
\begin{aligned}
N u & =\phi_{1}(\operatorname{Re}, \operatorname{Pr}), \\
N u_{m} & =\phi_{2}\left(\operatorname{Re}, \operatorname{Sc}, \frac{l \lambda}{U}\right),
\end{aligned}
$$

where $\operatorname{Re}=U l / \nu, S c=\nu / D$, and $\operatorname{Pr}=C_{p} \mu / k$. It is to be noted that the solutions of the heat and mass transfer equations would be exactly of the same form if the geometry and the boundary conditions were the same and there were no radioactive decay (i.e., $\lambda=0$ ). In such cases, the solution in one field could be obtained from the solution in the other field; that is, the mass transfer coefficients could be obtained from the heat transfer coefficients merely by replacing the Prandtl number by the Schmidt number and the Nusselt number by the Nusselt number for mass transfer. If there were radioactive decay, some error would be introduced in making 
the analogy. The magnitude of the error could be estimated if the solution of the mass equation were known. An approximate solution of Eq. (2.3) can be obtained by integrating Eq. (2.3) with respect to y from the wall surface to the outer edge of the boundary layer and substituting in this equation the value of the normal velocity component $v$ as obtained by integration from Eq. (2.1); thus

$$
\frac{d}{d x} \int_{0}^{\infty} u\left(n-n_{\infty}\right) d y=-D\left(\frac{\partial n}{\partial y}\right)_{y=0}-\lambda \int_{0}^{\infty} n d y
$$

where the subscript $\infty$ refers to the conditions in the bulk free stream, and the upper limit of the integration extends to the hypothetical edge of the mass concentration boundary layer in the position $x$. Note that Eq. (2.9) is merely a material-balance equation on a slab of thickness $\mathrm{dx}$ and width great enough to eliminate flow of material into the slab.

Dividing both sides of $\mathrm{Eq}$. (2.9) by $u_{\infty}$ and $\mathrm{n}_{\infty}$ gives

$$
\frac{d}{d x} \int_{0}^{\infty} \frac{u}{u_{\infty}}\left(\frac{n}{n_{\infty}}-1\right) d y=\frac{D}{u_{\infty}}\left(\frac{\partial}{\partial y} \frac{n}{n_{\infty}}\right)_{y=0}-\frac{\lambda}{u_{\infty}} \int_{0}^{\infty} \frac{n}{n_{\infty}} d y .
$$

This equation could be integrated if the velocity and particle concentration profiles in the hydrodynamic and mass boundary layers were known.

In the hydrodynamic boundary layer, the condition of no slip at the wall surface requires $u=0$ at $y=0$, and $u$ approaches the bulk free stream velocity at the edge of the boundary layer. The simplest velocity profile for the hydrodynamic boundary layer satisfying these minimum requirements can be taken as the linear approximation

$$
\frac{u}{u_{\infty}}=\frac{y}{\delta} \text {, }
$$

where $0 \leqslant y / \delta \leqslant 1$ and $\delta$ is the thickness of the hypothetical hydrodynamic boundary layer.

In the mass concentration boundary layer, the concentration approaches that of the bulk free stream at the edge of the boundary layer. Assuming $\mathrm{n}=0$ at $\mathrm{y}=0$, a linear approximation for the concentration distribution in the mass boundary layer can be taken as 


$$
\frac{\mathrm{n}}{\mathrm{n}_{\infty}}=\frac{\mathrm{y}}{\delta_{\mathrm{m}}}
$$

where $0 \leqslant y / \delta_{m} \leqslant 1$ and $\delta_{m}$ is the thickness of the hypothetical mass boundary layer. Note that both $\delta$ and $\delta_{m}$ are functions of $x$. For convenience,

$$
\frac{\delta_{m}}{\delta} \equiv \Delta,
$$

and it is assumed that $\Delta<1$; that is, the mass concentration boundary Layer thickness is smaller than the hydrodynamic boundary layer thickness. Substituting Eqs. (2.11, 2.12, and 2.13) into Eq. (2.10) and integrating from 0 tor $\hat{n}_{m}$ gives

$$
-\frac{\mathrm{d}}{\mathrm{dx}}\left(\frac{1}{6} \Delta^{2} \delta\right)=-\frac{\mathrm{D}}{\mathrm{u}_{\infty}} \frac{\mathrm{I}}{\Delta \delta}-\frac{\lambda \Delta \delta}{2 \mathrm{u}_{\infty}} .
$$

The thickness of the hydrodynamic boundary layer for the assumption of linear velocity distribution has been calculated, ${ }^{2}$ and it is given as

$$
\delta=\sqrt{12} \sqrt{v x / u_{\infty}}
$$

Substituting Eq. (2.15) into Eq. (2.14), performing the differentiation, and simplifying gives

$$
4 \mathrm{x} \Delta^{2} \cdot \frac{d \Delta}{d x}+\Delta^{3}-\frac{6 \lambda x}{u_{\infty}} \Delta^{2}-\frac{1}{S c}=0 .
$$

A solution for the case $\lambda=0$ is

$$
\Delta=\mathrm{Sc}^{-1 / 3}
$$

Based on a series solution of the form for the case $\lambda \neq 0$,

$$
\Delta=S c^{-1 / 3}\left(1+a_{1} x+a_{2} x^{2}+\ldots\right),
$$

it can be seen that

$$
\Delta=S^{-1 / 3}\left(1+\frac{S c^{1 / 3}}{7} \frac{6 \lambda x}{u_{\infty}}-\ldots\right),
$$

if

$$
(6 \lambda x) / u_{\infty}<1 \text { and } \Delta<1 \text {. }
$$


The decay constant, the bulk stream velocity, and the conduit length in most fission-product deposition problems are such that the requirement of (2.19) is satisfied.

The parameter $\Delta$ can be related to the mass transfer coefficient. From Eq. (2.6),

$$
h_{m}=\frac{D}{\Delta n}\left(\frac{\partial n}{\partial y}\right)_{y=0} .
$$

Since a linear concentration distribution was assumed in the mass boundary layer, the mass gradient at $\mathrm{y}=0$ is

$$
\left(\frac{\partial n}{\partial y}\right)_{y=0}=\frac{\Delta n}{\delta_{m}}=\frac{\Delta n}{\delta \triangle} .
$$

Substituting Eq. (2.21) into (2.20),

$$
h_{m}=\frac{D}{\delta} \frac{1}{\Delta}
$$

It is apparent from Eq. (2.22) that $h_{m}$ is inversely proportional to $\triangle$. With no radioactive decay (i.e., $\lambda=0$ ), Eq. (2.18) becomes

$$
\Delta=\mathrm{Sc}^{-1 / 3}
$$

Hence, the ratio of mass transfer coefficients with and without the radioactive decay becomes

$$
\frac{h_{m} \text { (with radioactive decay) }}{h_{m}(\text { no radioactive decay) }}=\frac{1}{1+\frac{6}{7} \frac{S c^{1 / 3} \lambda x}{1000}}
$$

Thus, the effects of radioactive decay on the mass-heat analogy are negligible, if

$$
\frac{6}{7} \frac{\mathrm{Sc}^{1 / 3} \lambda \mathrm{x}}{\mathrm{u}_{\infty}} \ll 1
$$

So far the effects have been considered of radioactive decay on the mass transfer coefficient for a developing boundary layer. The limiting case of fully established concentration and velocity distribution for flow through conduits is also of interest. The present analysis has been 
extended to include the limiting effects of radioactive decay on massheat analogy in round tubes, as described by Lyon. ${ }^{3}$

A mass balance equation for a differential volume of a round tube enclosed between $\mathrm{x}$ and $\mathrm{x}+\mathrm{dx}$ gives

$$
\begin{aligned}
-\frac{d W}{d x} & =h_{m} 2 \pi r_{W}\left(n_{m}-n_{W}\right)+ \\
\cdot & +\lambda 2 \pi \int_{0}^{r}{ }_{W} n r d r=N u_{m} D \pi\left(n_{m}-n_{W}\right)+\lambda 2 \pi \int_{0}^{r_{W}} n r d r,
\end{aligned}
$$

where

$\mathrm{W}=\pi r_{\mathrm{W}}^{2} u_{m} \mathrm{n}_{\mathrm{m}}=$ flow rate of particles, particles/sec,

$h_{\text {III }}=$ mass transfer coefficient, $\mathrm{cm} / \mathrm{sec}$,

$\mathrm{n}=$ local concentration, particles $/ \mathrm{cm}^{3}$,

$\mathrm{n}_{\mathrm{W}}=$ concentration at the wall (i.e., at $r=r_{\mathrm{W}}$ ), particles $/ \mathrm{cm}^{3}$,

$\mathrm{n}_{\mathrm{m}}=$ mixed-mean concentration, particles $/ \mathrm{cm}^{3}$,

$\mathrm{Nu}_{\mathrm{m}}=\mathrm{h}_{\mathrm{m}} 2 \mathrm{r}_{\mathrm{w}} / \mathrm{D}=$ Nusselt number for mass transfer, dimensionless,

$r_{\mathrm{w}}=$ radius of tube, $\mathrm{cm}$,

$r=$ radial distance from the tube axis, $\mathrm{cm}$,

$u_{\mathrm{m}}=$ mixed-mean velocity.

Rearranging Eq. (2.26) and writing $n=n_{w}+\left(n-n_{W}\right)$ gives

$$
-\frac{d W / d x}{\pi D\left(n_{m}-n_{W}\right)}=N u_{m}+\frac{\lambda r_{W}^{2}}{D}\left(\frac{n_{W}}{n_{m}-n_{W}}+\frac{2}{r_{W}^{2}} \int_{0}^{r_{W}} \frac{n-n_{W}}{n_{m}-n_{W}} r d r\right) .
$$

Thus, in order to determine the effects of radioactive decay on mass transfer, $\mathrm{Nu}_{\mathrm{m}}$ is compared with

$$
\frac{\lambda r_{W}^{2}}{D}\left(\frac{\dot{n}_{W}}{n_{m}-n_{W}}+\frac{2}{r_{W}^{2}} \int_{0}^{r_{W}} \frac{n-n_{W}}{n_{m}-n_{w}} r d r\right)
$$

Note that the second term in the parentheses is almost unity for turbulent flow; and assuming $\mathrm{n}_{\mathrm{w}}=0$, the effect of radioactive decay on the mass-heat 
analogy becomes negligible, if

$$
\frac{1}{N u_{m}} \frac{\lambda r_{W}^{2}}{D} \ll 1 \text {. }
$$

In the case of laminar flow, the value of the integral in (2.28) depends on the velocity profile. The results for fully established velocity and concentration profile far downstream in round tubes are: ${ }^{3}$

1. For the slug flow, with constant flux at the wall and fully established velocity and concentration profiles, taking $\mathrm{Nu}_{\mathrm{m}}=8$ and $u / u_{m}=1$, the mass-heat analogy with standard heat transfer equations is applicable if

$$
\frac{\lambda r_{w}^{2}}{D}\left(\frac{n_{w}}{n_{m}-n_{w}}+1\right) \ll 1 ;
$$

or, for $n_{W}-0$, if

$$
\frac{I}{8} \frac{\lambda r^{2}}{D} \ll 1 .
$$

2. For laminar flow with constant flux at the wall, taking

$$
\mathrm{Nu} u_{\mathrm{m}}=\frac{48}{11}
$$

and a parabolic velocity distribution, the heat-mass analogy is applicable if

$$
\frac{11}{48} \frac{\lambda r_{W}^{2}}{D}\left(\frac{n_{w}}{r_{m}-n_{w}}+\frac{8}{11}\right) \ll 1 ;
$$

or, for $\mathrm{n}_{\mathrm{w}}=0$, if

$$
\frac{1}{6} \frac{\lambda r_{W}^{2}}{D} \ll 1 .
$$

3. For laminar flow with constant concentration at the wall, taking $\mathrm{Nu}_{\mathrm{m}}=3.66$ and a parabolic velocity distribution, the heat-mass analogy is applicable if 


$$
\frac{1}{3.66} \frac{\lambda r_{W}^{2}}{D}\left(\frac{n_{w}}{n_{m}-n_{W}}+0.709\right) \ll 1
$$

or, for $n_{W}=0$, if

$$
\frac{1}{5.16} \frac{\lambda r_{W}^{2}}{D} \ll 1
$$

In heat transfer problems, the walls of the conduit are a perfect sink,-but, in-the-case of fission-product deposition, the particles arriving at the wall surface may not all deposit on the wall surface. To treat such cases, a factor $P$, defined as the probability that a particle sticks on the wall surface is introduced láter in the text. In terms of particle concentration in the stream, $P$ is given as

$$
\mathrm{P}=\frac{(\text { mean concentration })-(\text { wall concentration })}{(\text { mean concentration })}=\frac{\mathrm{n}_{\mathrm{m}}-\mathrm{n}_{\mathrm{W}}}{\mathrm{n}_{\mathrm{m}}}
$$

and

$$
1-P=\frac{n_{w}}{n_{m}}
$$

Hence, $P$ can be considered as a factor of absorptivity, and $(I-P)$ as a factor of reflectivity of the wall surface for the particles arriving at the wall; that is, $P=I$ for a perfect sink, and $P=0$ for a perfectly reflecting surface or for particles which do not deposit on the wall surface.

The effects of radioactive decay on the heat-mass analogy for the cases when the wall is not a perfect sink (i.e., $P<1$ ) are also of interest.... Rearranging_Eq. (2.27), substituting the definitions of .W and $P$, and defining $h_{m} / u_{m}$ as the stanton number gives

$$
-\frac{d\left(\log _{e} n_{m}\right)}{a\left(\frac{x}{r_{w}}\right)}=2 \dot{S} t P+\frac{\lambda r_{w}}{u_{m}}\left(1-P+P \frac{2}{r_{W}^{2}} \int_{0}^{r_{w}} \frac{n-n_{W}}{n_{m}-n_{W}} r d r\right) .
$$


Since,

$$
\frac{2}{r_{W}^{2}} \int_{0}^{r_{w}} \frac{n-n_{w}}{n_{m}-n_{w}} r d r \cong 1,
$$

the heat-mass analogy is applicable, if

$$
\frac{\lambda r_{w}}{u_{m}} \ll 2 \text { PSt } \text {. }
$$

\section{MASS TRANSITR CORITICITNTS}

In the preceding section it was shown that when the geometry, the governing equations, and the boundary conditions for the heat and mass transfer problems are similar, a mass transfer coefficient could be obtained from the solution of the heat transfer equation simply by replacing the Prandtl number by the Schmidt number and the Nusselt number for heat transfer by the Nusselt number for mass transfer. Solutions are available for heat transfer coefficients for various simple geometries under laminar and turbulent conditions. The local mass transfer coefficients, as obtained from the corresponding heat transfer solutions, are given below for various geometries and flow conditions.

1. Flat plate with laminar flow parallel to the plate surface; Pohlhauscn's solution: 4

$$
\frac{h_{m} x}{D}=0.324\left(\frac{U \rho x}{\mu}\right)^{0.5}\left(\frac{\mu}{\rho D}\right)^{1 / 3} .
$$

2. Flat plate with turbulent flow parallel to the plate surface: ${ }^{4}$

$$
\frac{h_{m} x}{D}=0.0292\left(\frac{U \rho x}{\mu}\right)^{0.8}\left(\frac{\mu}{\rho D}\right)^{1 / 3} .
$$

3. Laminar flow inside circular tubes; the fully developed parabolic velocity profile is established at the entrance to the tube; the simplified Graetz solution: ${ }^{4}$ 


$$
\frac{h_{m} d}{D}=1.077\left(\frac{U \rho d}{\mu} \frac{\mu}{\rho D} \frac{d}{x}\right)^{1 / 3},
$$

for $\operatorname{Re} S c(d / x)>100$, that is, the entrance regions where the boundary layer is developing, and

$$
\frac{\mathrm{h}_{\mathrm{m}} \mathrm{d}}{\mathrm{D}}=3.66
$$

for $\operatorname{Re} \mathrm{Sc}(\mathrm{d} / \mathrm{x})<10$, where $\mathrm{d}$ is the tube inside diameter, $\mathrm{cm}$.

4. Turbulent flow inside the tubes; the Dittus and Boelter equation has been extensively used in correlating the heat transfer in circular tubes for fully developed turbulent flow and moderate temperature differences between the gas stream and the tube surface. Based on fully developed hydrodynamic and mass boundary layers (i.e., no entrance effects), the equation for mass transfer is: ${ }^{4}$

$$
\frac{h_{m}{ }^{d}}{D}=0.023\left(\frac{U \rho d}{\mu}\right)^{0.8}\left(\frac{\mu}{\rho D}\right)^{0.3} .
$$

Solving this equation for $h_{m}$ gives

$$
h_{m}=0.023 \frac{D^{0 .{ }^{7}} \rho^{0.5} U^{0.8}}{\mu^{0.5} d^{0.2}}
$$

Note that the mass transfer coefficient is independent of the distance for this particular case, since a fully developed boundary layer is assumed. This is valid in the regions away from the tube entrance. The mass transfer coefficients in the regions near the entrance are higher than that given by Eq. (3.6). The heat transfer experiments have shown that the local heat transfer coefficients with turbulent flow in the entrance region, say, at three diameters from the tube inlet, are about 40 and $10 \%$ higher than those at greater distances for the Reynolds numbers $10^{4}$ and $10^{5}$, respectively. ${ }^{4}$ The variation is less than $10 \%$ at distances about 15 diameters from the inlet. Assuming that the same applies for the mass transfer, the mass transfer coefficient can be assumed to be independent of the distance beyond about 15 diameters from the tube inlet. 
If the thickness of the boundary layer is small compared with the diameter of the tube, a flat-plate model can be used for estimating the mass transfer coefficients for the inlet region where the boundary layers are developing. The mass transfer coefficient for a given gas and particle type, passage size, pressure, and temperature condition can be expressed, for the cases discussed above, as

$$
h_{m} \equiv \mathrm{C} \frac{1}{\mathrm{x}^{\mathrm{r}}},
$$

where the exponent $r$ would be zero for the case of fully developed turbulent flow.

4. ANALYSIS OF FISSION-PRODUCT DEPOSITION RATE WITH THE MASS TRANSFER COEFFICIENT INDEPENDENT OF DISTANCE

A source is considered that releases only one type of fission product into a gas stream flowing through a conduit. The fission product that enters the stream directly from the source will be referred to as the "precursor" for convenience. The precursor will decay to daughter products as it moves along the stream.

The following assumptions are made for the purposes of analysis:

1. The concentration of the precursor in the gas stream at the origin is known.

2. The particles are all of the same size.

3. There is no interaction between the precursor and its daughter products to affect deposition.

4. The transients have passed, and steady-state deposition rates are established.

5. The particles are so small that the effects of external forces are negligible.

6. There are no thermal forces acting on the particles (i.e., isothermal flow).

7. There are no electrostatic forces acting on the particles.

8. Diffusion resulting from random motion of the particles is the principal mechanism for deposition. 
9. The heat-mass analogy is applicable for deposition by diffusion.

10. Particle concentration in the gas stream is so low that there is no agglomeration.

11. There is no condensation.

12. The crosi-sectional area of the conduit is constant.

13. The mass transfer coefficient is independent of the distance (i.e., fully developed turbulent flow and no entrance effects).

14. The circuit is open; that is, the gas is not recirculating.

For a given type of particle, gas velocity, passage dimension, temperature, and pressure, the mass transt'er coet'ticients given in the previous section can be expressed as (see Eq. 3.7)

$$
h_{m}=\frac{r}{x^{r}} \text {, }
$$

and for the case of the mass transfer coefficient independent of the distance, taking $r=0$, gives

$$
h_{m}=\frac{C}{x^{0}}=C,
$$

where the value of $\mathrm{C}$ in Eq. (4.2) is the same as that given by Eq. (3.6).

Particles arriving at the wall surface after diffusion through the laminar boundary layer may not all deposit on it; some may return to the stream; that is, the wall surface is not a perfect sink. By introducing $P$ as the probability that an atom or particle will deposit (stick) on the wall surface, where

$$
\mathrm{F}=\frac{\mathrm{n}_{\mathrm{m}}-\mathrm{n}_{\mathrm{w}}}{\mathrm{n}_{\mathrm{m}}},
$$

$\mathrm{n}_{\mathrm{m}}$ is the mixed mean concentration of particles in the stream at $\mathrm{x}$, particles $/ \mathrm{cm}^{3}$, and $n_{\mathrm{w}}$ is the concentration of particles in the gas stream at the wall, particles $/ \mathrm{cm}^{3}$, and assuming that

$$
0 \leqslant P \leqslant 1
$$

it is found that, for a given type and size of particle and wall surface condition, if $P$ is independent of the distance $x$ (i.e., $n_{W} / n_{m}=$ constant), 
the rate of deposition of particles on the wall surface at $\mathrm{x}$ in particles per $\mathrm{cm}^{2} \cdot \mathrm{sec}$

$$
\mathrm{Q}(\mathrm{x})=\mathrm{C}\left(\mathrm{n}_{\mathrm{m}}-\mathrm{n}_{\mathrm{w}}\right)=\mathrm{PCn_{m }},
$$

where only $n_{m}$ is a function of $x$.

For convenience in the subsequent analysis, the subscript $m$ will be omitted, but the following subscripts will be used: 0 , to refer to precursor (i.e., particle which enters the gas stream first); 1 , to refer to first daughter product; and 2, to refer to the second daughter product. The precursor, its transport in the gas stream, and its deposition on the wall surface will be considered first. A mass balance equation for the concentration of the precursor in the gas stream at a distance $x$ from the origin can be stated as follows:

(Rate of increase of particles with time) = (net rate of

$$
\begin{aligned}
\text { gain by convection) } & - \text { (rate of loss by decay) - } \\
& - \text { (rate of loss by deposition). }
\end{aligned}
$$

Substituting the mathematical expressions in this equation for the steadystate condition gives

$$
\begin{aligned}
\frac{\mathrm{d}}{\mathrm{d} \theta}\left(\mathrm{A \Delta x} \mathrm{n}_{0}\right) & =0 \\
& =-\frac{\mathrm{d}}{\mathrm{dx}}\left(A \mathrm{AU}_{0}\right) \Delta \mathrm{x}-\lambda_{0} A \Delta \mathrm{x} \mathrm{n}_{0}-\mathrm{a} \Delta \mathrm{x} \mathrm{F}_{0} \mathrm{C}_{0} \mathrm{n}_{0},
\end{aligned}
$$

where

$A=$ cross-section area for flow, $\mathrm{cm}^{2}$,

$a=$ dcposition surface per unit length of conduit, $\mathrm{cm}^{2} / \mathrm{cm}$,

$\mathrm{C}_{0}=$ mass transfer coefficient as defined by Eq. (4.I), cm/sec,

$\lambda_{0}=$ the decay constant, $\sec ^{-1}$.

Simplifying Eq. (4.6) gives

$$
\frac{d n_{0}}{d x}+\frac{1}{U}\left(\lambda_{0}+\frac{a}{A} P_{0} C_{0}\right) n_{0}=0 .
$$

By definition,

$$
\mathrm{d}_{\mathrm{e}} \equiv \frac{4 \mathrm{~A}}{\mathrm{a}}
$$


or

$$
\frac{a}{A}=\frac{4}{d_{e}}
$$

Substituting Eq. (4.8) into Eq. (4.7) gives

$$
\frac{d n_{0}}{d x}+\frac{1}{U}\left(\lambda_{0}+\frac{4 \mathrm{P}_{0} c_{0}}{d_{e}}\right) n_{0}=0 .
$$

Integrating Eq. (4.9) with the boundary condition $n_{0}=N_{0}$ for $x=0$, gives

$$
n_{0}=N_{0} e^{-\alpha_{0} x}
$$

where

$$
\begin{aligned}
& \alpha_{0} \equiv \frac{1}{U}\left(\lambda_{0}+\frac{4 P_{0} C_{0}}{d_{e}}\right), \\
& \mathrm{N}_{\mathrm{O}} \text { = concentration of the precursor in the gas stream at the origin, }
\end{aligned}
$$

The deposition rate of the precursor in particles $/ \mathrm{cm}^{2}$ becomes

$$
Q_{0}=P_{0} C_{0} n_{0}=N_{0} P_{0} C_{0} e^{-\alpha_{0} x}
$$

Particles deposited on the surface will continue to decay to daughter products. If $\mathrm{M}_{O}$ is the concentration of the precursor on the wali surface at a distance $x$ from the origin, in particles $/ \mathrm{cm}^{2}$, a mass balance equation for the concentration of the precursor on the wall surface at steady state is

$$
\frac{d M_{O}}{d \theta}=Q_{0}-\lambda_{O} M_{0}=0
$$

Hence,

$$
M_{0}=\frac{Q_{0}}{\lambda_{0}}
$$

From Eqs. (4.11) and (4.12), the concentration of the precursor on the 
surface, in particles $/ \mathrm{cm}^{2}$, as a function of the distance is

$$
M_{0}=N_{0} \frac{P_{0} C_{0}}{\lambda_{0}} e^{-\alpha_{0} x}
$$

With the concentration of the precursor known, the concentration of the first daughter product on the surface can be evaluated. A mass balance equation for the first daughter product can be stated as:

(Rate of increase of particles with time) = (net rate of gain by convection) + (rate of gain due to decay from the precursor) - (rate of loss by decay) -

$$
\text { - (rate of loss by deposition). }
$$

Substituting the mathematical expressions in Eq. (4.14) for steady-state conditions gives

$$
\begin{aligned}
\frac{\mathrm{d}}{\mathrm{d} \theta}\left(\mathrm{A \Delta x} \mathrm{n}_{1}\right) & =0 \\
= & -\frac{\mathrm{d}}{\mathrm{dx}}\left(A U \mathrm{n}_{1}\right) \Delta \mathrm{x}+\lambda_{0} A \Delta \mathrm{x} \mathrm{n}_{0}-\lambda_{1} A \Delta x \mathrm{n}_{1}- \\
& -a \Delta x P_{1} C_{1} n_{1},
\end{aligned}
$$

where $\mathrm{n}_{1}$ is the concentration of the first daughter product in the gas stream at a distance $x$ from the origin, in particles $/ \mathrm{cm}^{3}$. Simplifying Eq. (4.15) gives

$$
\frac{d n_{1}}{d x}+\frac{I}{U}\left(\lambda_{I}+\frac{a P_{1} c_{1}}{A}\right) n_{1}=\frac{\lambda_{0}}{U} n_{0},
$$

and substituting Eqs. (4.8) and (4.10) into Eq. (4.16) gives

$$
\frac{d n_{1}}{d x}+\alpha_{1} x=\frac{N_{O} \lambda_{O}}{U} e^{-\alpha_{0} x}
$$

where

$$
\alpha_{0} \equiv \frac{I}{U}\left(\lambda_{0}+\frac{4 P_{0} C_{0}}{d_{e}}\right) \quad \text { and } \quad \alpha_{I} \equiv \frac{I}{U}\left(\lambda_{I}+\frac{4 P_{I} C_{1}}{d_{e}}\right) \text {. }
$$

Equation (4.17) can be made an exact differential, as follows: 


$$
e^{-\alpha_{1} x} \frac{d}{d x}\left(n_{1} e^{\alpha_{1} x}\right)=\frac{N_{0} \lambda_{0}}{U} e^{-\alpha_{0} x}
$$

or

$$
\frac{d}{d x}\left(n_{1} e^{\alpha_{1} x}\right)=\frac{N_{0} \lambda_{0}}{U} e^{-\left(\alpha_{0}-\alpha_{1}\right) x} .
$$

Integrating $\mathrm{Eq}$. (4.20) from $x=0$ to $x$, with the condition $n_{1}=0$ at $\mathrm{x}=0$, gives

$$
\dot{n}_{1}=\frac{N_{\Omega} \lambda_{\Omega}}{U} \frac{e^{-\alpha_{\odot} x}-e^{-\alpha_{1} x}}{\left(\alpha_{1}-\alpha_{0}\right)} .
$$

The rate of deposition of the first daughter on the wall surface is:

$$
Q_{1}=P_{1} C_{1} n_{1}=P_{1} C_{1} \frac{N_{0} \lambda_{0}}{U} \frac{e^{-\alpha_{0} x}-e^{-\alpha_{1} x}}{\alpha_{1}-\alpha_{0}} .
$$

If $M_{1}$ is concentration of the first daughter product on the wall surface at $x$, in particles $/ \mathrm{cm}^{2}$, a mass balance equation for the concentration of the first daughter product can be stated as follows:

(Rate of increase of particles with time) = (rate of gain

$$
\begin{aligned}
& \text { due to deposition of first daughter) + (rate } \\
& \text { of gain due to decay of precursor on wall) - }
\end{aligned}
$$

$$
\text { - (rate of loss by decay). }
$$

Substituting the mathematical expression for steady state conditions gives

$$
\frac{d M_{1}}{d \theta}=0=Q_{1}+\lambda_{0} M_{0}-\lambda_{1} M_{1}=0
$$

or

$$
M_{1}=\frac{\lambda_{0}}{\lambda_{1}} M_{0}+\frac{1}{\lambda_{1}} Q_{1} \text {. }
$$

Substituting Eqs. (4.13) and (4.22) into Eq. (4.24) gives

$$
\mathrm{M}_{1}=\mathrm{N}_{\mathrm{O}} \cdot \frac{\mathrm{P}_{\mathrm{O}} \mathrm{C}_{\mathrm{O}}}{\lambda_{1}} \mathrm{e}^{-\alpha_{\mathrm{O}} \mathrm{X}}+\mathrm{N}_{\mathrm{O}} \frac{\mathrm{P}_{1} \mathrm{C}_{1}}{\lambda_{1}} \frac{\lambda_{\mathrm{O}}}{\mathrm{U}} \frac{\mathrm{e}^{-\alpha_{\mathrm{O}} \mathrm{X}}-\mathrm{e}^{-\alpha_{1} \mathrm{X}}}{\alpha_{1}^{\prime}-\alpha_{0}} .
$$


The concentration of the second daughter product on the surface can be evaluated following a similar procedure. The mass balance equation for the concentration of the second daughter product in the gas stream is the same as Eq. (4.16) except that the subscript 0 is changed to 1 and the subscript 1 to 2 . Hence,

$$
\frac{d n_{2}}{d x}+\frac{1}{U}\left(\lambda_{2}+\frac{a P_{2} C_{2}}{A}\right) n_{2}=\frac{\lambda_{1}}{U} n_{1}
$$

Substituting Eqs. (4.8) and (4.21) into Eq. (4.26) gives

$$
\frac{d n_{2}}{d x}+\frac{1}{U}\left(\lambda_{2}+\frac{4 P_{2} C_{2}}{a_{e}}\right) n_{2}=\frac{\lambda_{1}}{U} \frac{N_{O} \lambda_{O}}{U} \frac{e^{-\alpha_{O} x}-e^{-\alpha_{1} x}}{\alpha_{1}-\alpha_{2}},
$$

where

$$
\alpha_{2} \equiv \frac{1}{U}\left(\lambda_{2}+\frac{4 \mathrm{P}_{2} \mathrm{C}_{2}}{\dot{d}_{\mathrm{e}}}\right) .
$$

Equation (4.27) becomes

$$
\frac{d n_{2}}{d x}+\alpha_{2} n_{2}=\frac{\lambda_{1}}{U} \frac{N_{O} \lambda_{0}}{U} \frac{e^{-\alpha_{O} x}-e^{-\alpha_{1} x}}{\alpha_{1}-\alpha_{0}},
$$

which becomes an exact differential:

$$
\frac{d}{d x}\left(n_{2} e^{\alpha_{2} x}\right)=\frac{\lambda_{1}}{U} \frac{N_{0} \lambda_{0}}{U} \frac{e^{-\left(\alpha_{0}-\alpha_{2}\right) x}-e^{-\left(\alpha_{1}-\alpha_{2}\right) x}}{\alpha_{1}-\alpha_{0}}
$$

Integrating Eq. (4.30) from $x=0$ to $x$ with the condition $n_{2}=0$ at $x=0$ gives

$$
\mathrm{n}_{2}=\frac{\lambda_{1}}{\mathrm{U}} \frac{\mathrm{N}_{0} \lambda_{0}}{\mathrm{U}} \frac{1}{\alpha_{1}-\alpha_{0}}\left(\frac{\mathrm{e}^{-\alpha_{2} \mathrm{x}}-\mathrm{e}^{-\alpha_{1} \mathrm{x}}}{\alpha_{2}-\alpha_{1}}-\frac{\mathrm{e}^{-\alpha_{2} \mathrm{x}}-\mathrm{e}^{-\alpha_{0} \mathrm{x}}}{\alpha_{2}-\alpha_{0}}\right)
$$

The deposition rate of the second daughter product is

$$
\mathrm{Q}_{2}=\mathrm{P}_{2} \mathrm{C}_{2} \mathrm{n}_{2}
$$

The steady-state concentration of the second daughter product is given by an equation similar to Eq. (4.24), except that the subscripts are changed as for Eq. (4.26). Hence 


$$
M_{2}=\frac{\lambda_{1}}{\lambda_{2}} M_{1}+\frac{1}{\lambda_{2}} Q_{2} .
$$

Substituting Eq. (4.32) into Eq. (4.33) gives

$$
\mathrm{M}_{2}=\frac{\lambda_{1}}{\lambda_{2}} \mathrm{M}_{1}+\frac{\mathrm{P}_{2} \mathrm{C}_{2}}{\lambda_{2}} \mathrm{n}_{2} \text {, }
$$

and substituting Eqs. (4.25) and (4.31) into Eq. (4.34) gives

$$
\begin{aligned}
\mathrm{M}_{2}= & \mathrm{N}_{0} \frac{\mathrm{P}_{0} \mathrm{C}_{\mathrm{O}}}{\lambda_{2}} \mathrm{e}^{-\alpha_{0} \mathrm{X}}+\mathrm{N}_{0} \frac{\mathrm{P}_{1} \mathrm{C}_{1}}{\lambda_{2}} \frac{\lambda_{0}}{\mathrm{U}} \frac{\mathrm{e}^{-\alpha_{0} \mathrm{x}}-\mathrm{e}^{-\alpha_{1} \mathrm{x}}}{\alpha_{1}-\alpha_{\circ}}+ \\
& +\mathrm{N}_{\cong} \frac{\mathrm{P}_{2} \mathrm{C}_{2}}{\lambda_{2}} \frac{\lambda_{0}}{\mathrm{U}} \frac{\lambda_{1}}{\mathrm{U}} \frac{1}{\alpha_{1}-\alpha_{0}}\left(\frac{\mathrm{e}^{-\alpha_{2} \mathrm{x}}-\mathrm{e}^{-\alpha_{1} \mathrm{x}}}{\alpha_{2}-\alpha_{1}}-\frac{\mathrm{e}^{-\alpha_{2} \mathrm{x}}-\mathrm{e}^{-\alpha_{0} \mathrm{x}}}{\alpha_{2}-\alpha_{0}}\right),
\end{aligned}
$$

where $\mathrm{M}_{2}$ is the concentration of the second daughter product at a distance $x$ from the origin, in particles $/ \mathrm{cm}^{2}$. If it is assumed that the precursor is released into the gas stream at a constant rate, the concentration of the precursor, in particles $/ \mathrm{cm}^{3}$, in the gas stream at the origin is given by:

$$
\mathrm{N}_{\mathrm{O}}=\frac{\mathrm{R}}{\mathrm{AU}},
$$

where

$$
\begin{aligned}
& R=\text { release rate, particles } / \mathrm{sec}, \\
& A=\text { cross-sectional area for flow, } \mathrm{cm}^{2}, \\
& U=\text { coolant velocity, } \mathrm{cm} / \mathrm{sec} .
\end{aligned}
$$

\section{DEPOSITION OF DAUGHTERS OF THE NOBLE GASES}

It was assumed that the noble gases would not deposit on the wall surfaces but their daughter products would. The equations in Section 4. apply to the noble gases simply by substituting $P_{O}=0$. Hence, Eq. (4.13). becomes

$$
\mathrm{M}_{\mathrm{O}}=0 \text {, }
$$


which is consistent with the assumption that the noble gases do not deposit.

Equation (4.25) for the deposition of the first daughter product becomes, for daughters of noble gases,

$$
M_{1}=N_{0} \frac{P_{1} C_{1}}{\lambda_{I}} \frac{\lambda_{0}}{U} \frac{e^{-\alpha_{0} x}-e^{-\alpha_{1} x}}{\alpha_{1}-\alpha_{0}}
$$

and Eq. (4.35) for the deposition of the second daughter becomes

$$
\begin{aligned}
\mathrm{M}_{2}= & \mathrm{N}_{0} \frac{\mathrm{P}_{1} \mathrm{C}_{1}}{\lambda_{2}} \frac{\lambda_{0}}{\mathrm{U}} \frac{\mathrm{e}^{-\alpha_{0} \mathrm{x}}-\mathrm{e}^{-\alpha_{1} \mathrm{x}}}{\alpha_{1}-\alpha_{0}}+ \\
& +\mathrm{N}_{0} \frac{\mathrm{P}_{2} \mathrm{C}_{2}}{\lambda_{2}} \frac{\lambda_{0}}{\mathrm{U}} \frac{\lambda_{1}}{\mathrm{U}} \frac{1}{\alpha_{1}-\alpha_{0}}\left(\frac{\mathrm{e}^{-\alpha_{2} \mathrm{x}}-\mathrm{e}^{-\alpha_{1} \mathrm{x}}}{\alpha_{2}-\alpha_{1}}-\frac{\mathrm{e}^{-\alpha_{2} \mathrm{x}}-\mathrm{e}^{-\alpha_{0} \mathrm{x}}}{\alpha_{2}-\alpha_{0}}\right),
\end{aligned}
$$

where

$$
\begin{aligned}
& \alpha_{0}=\frac{\lambda_{0}}{U}, \\
& \alpha_{1}=\frac{1}{\bar{U}}\left(\lambda_{1}+\frac{4 \mathrm{P}_{1} \mathrm{C}_{1}}{\mathrm{~d}_{\mathrm{e}}}\right), \\
& \alpha_{2}=\frac{1}{\mathrm{U}}\left(\lambda_{2}+\frac{4 \mathrm{P}_{2} \mathrm{C}_{2}}{\mathrm{~d}_{\mathrm{e}}}\right) .
\end{aligned}
$$

\section{DEPOSITION RATE NEAR THE ENTRANCE}

In the preceding analysis the mass transfer coefficient was assumed to be independent of the distance from the source, but in the regions near the entrance, the mass transfer coefficients vary with the distance because the boundary layer is rapidly developing. It was shown in Section 3 that for a given gas and particle type, gas velocity, passage size, pressure, and temperature, the mass transfer coefficient could be expressed as 


$$
h_{m}=\frac{c}{x^{r}}
$$

and the values of $\mathrm{C}$ and the exponent $\mathrm{r}$ could be obtained for laminar flow from the relations given by Eqs. (3.1) through (3.4) for the particular geometry and flow conditions considered.

The procedure and the basic differential equations for evaluating the deposition rates for this case are essentially the same as those used in Section 4. A mass transfer coefficient, as defined by Eq. (6.1), which is a function of the distance with the exponent $r$ constant, is used instead of the constant mass transfer coefficient used in the previous analysis.

Replacing $C$ by $C / x^{r}$ in Eq. (4.9) gives

$$
\frac{d n_{0}}{d x}+\frac{1}{U}\left(\lambda_{0}+\frac{4 P_{0} C_{0}}{d_{e}} \frac{I}{x^{r}}\right) n_{0}=0,
$$

and the following definitions are used to simplify the equations:

$$
\begin{gathered}
f_{0}(x) \equiv \frac{1}{U}\left(\lambda_{0}+\frac{\left.4 P_{0} C_{0} \frac{I_{i}}{d_{e}}\right)}{x^{r}}\right) \\
F_{0}(x) \equiv \int_{0}^{x} f_{0}(x) d x=\frac{1}{U}\left[\lambda_{0}+\frac{4 P_{0} C_{0}}{(1-r) d_{e}} \frac{1}{x^{x}}\right] x .
\end{gathered}
$$

Integrating Eq. (6.2) from $\mathrm{x}=0$ to $\mathrm{x}$ with the boundary condition $\mathrm{n}_{0}=\mathrm{N}_{0}$ for $\mathrm{x}=0$ gives

$$
n_{0}=N_{0} e^{-F_{0}(x)}
$$

The concentration of the precursor on the wall surface is, based on Eq. $(4.12)$,

$$
\mathrm{M}_{0}=\frac{\mathrm{Q}_{0}}{\lambda_{0}}=\frac{\mathrm{P}_{0} \mathrm{C}_{0}}{\lambda_{0}} \frac{1}{\mathrm{x}^{r}} \mathrm{n}_{0}
$$

Substituting $\mathrm{n}_{0}$ from Eq. (6.4) into Eq. (6.5) gives 


$$
M_{0}=N_{0} \frac{P_{0} C_{0}}{\lambda_{0}} \frac{I}{x^{r}} e^{-F_{0}(x)}
$$

Note that Eq. (6.6) becomes identical to Eq. (4.13) for $r=0$.

The differential equation for the concentration of the first daughter product in the gas stream is, based on Eq. (4.16),

$$
\frac{d n_{1}}{d x}+f_{1}(x) n_{1}=\frac{N_{0} \lambda_{0}}{U} e^{-F_{0}(x)}
$$

where

$$
f_{1}(x) \equiv \frac{1}{U}\left(\lambda_{1}+\frac{4 P_{1} C_{1}}{d_{e}} \frac{1}{x^{r}}\right)
$$

Integrating Eq. (6.7) from $\mathrm{x}=0$ to $\mathrm{x}$ gives

$$
\begin{aligned}
n_{1} \exp \left[\int_{0}^{x} f_{1}(x) d x\right] & =\text { constant } \\
& +\frac{N_{0} \lambda_{0}}{U} \int_{0}^{x} \exp \left[-F_{0}(x)\right] \exp \left[\int_{0}^{x} f_{1}(x) d x\right] d x,
\end{aligned}
$$

and, by definition,

$$
F_{1}(x) \equiv \int_{0}^{x} f_{1}(x) d x=\frac{1}{U}\left[\lambda_{1}+\frac{4 P_{1} C_{1}}{(1-r) d_{e}} \frac{1}{x^{r}}\right] x .
$$

Equation (6.9) becomes

$$
\mathrm{n}_{1} \mathrm{e}^{\mathrm{F}_{1}(\mathrm{x})}=\mathrm{constan} t+\frac{\mathrm{N}_{0} \lambda_{0}}{U} \frac{1}{f_{1}(x)-f_{0}(x)} e^{F_{1}(x)-F_{0}(x)}
$$

The boundary condition $\mathrm{n}_{1}=0$ for $\mathrm{x}=0$ gives the integration constant as

$$
\text { constant }=-\frac{N_{0} \lambda_{0}}{U} \frac{1}{f_{I}(x)-f_{0}(x)} .
$$

Substituting Eq. (6.12) into Eq. (6.11) and rearranging gives 


$$
\mathrm{n}_{1}=\frac{\mathrm{N}_{0} \lambda_{0}}{\mathrm{U}} \frac{\mathrm{e}^{-\mathrm{F}_{0}(\mathrm{x})}-\mathrm{e}^{-\mathrm{F}_{1}(\mathrm{x})}}{\mathrm{f}_{1}(\mathrm{x})-\mathrm{f}_{\mathrm{O}}(\mathrm{x})}
$$

Note that for $r=0, E q .(6.13)$ is identical with Eq. (4.21).

The concentration of the first daughter product on the wall surface is, based on Eq. (4.24),

$$
\begin{aligned}
\mathrm{M}_{1} & =\frac{\lambda_{0}}{\lambda_{1}} \mathrm{M}_{0}+\frac{1}{\lambda_{1}} Q_{1} \\
& =\frac{\lambda_{0}}{\lambda_{1}} \mathrm{M}_{0}+\frac{\mathrm{P}_{1} \mathrm{C}_{1}}{\lambda_{1}} \frac{1}{\mathrm{x}^{\mathrm{r}}} \mathrm{n}_{1} .
\end{aligned}
$$

Substituting Eqs. (6.6) and (6.13) into Eq. (6.14) gives

$$
M_{1}=N_{0} \frac{P_{0} C_{0}}{\lambda_{1}} \frac{1}{x^{r}} e^{-F_{0}(x)}+N_{0} \frac{P_{1} C_{1}}{\lambda_{1}} \frac{\lambda_{0}}{U} \frac{1}{x^{r}} \frac{e^{-F_{0}(x)}-e^{-F_{1}(x)}}{f_{1}(x)-f_{0}(x)} .
$$

For $r=0$, Eq. (6.15) is the same as Eq. (4.25).

\section{FFFECTS OF CLOSED LOOP ON DEPOSITION RATE}

The equations derived in the previous sections were for an open circuit; that is, the gas entering was not recirculated. In most applications, however, a closed loop is used, and the gas is recirculated. In such cases the fission products that do not deposit upon the completion of one complete cycle will be added to the concentration of the gas stream in the following cycle. The procees will continue until the concentration is built up in the gas stream to the point that the total rate of deposition during one complete cycle equals the total release rate by the source. The equilibrium concentration rate for a closed loop can be evaluated in the following manner. Let

$$
\begin{aligned}
\mathrm{L}= & \text { total length of the loop, } \\
\mathrm{N}_{\mathrm{O}}= & \text { open-circuit (i.e., no recirculation) concentration of the precursor } \\
& \text { in the gas stream at the origin, and } \\
N_{c}= & \text { closed-loop equilibrium concentration of the precursor at the } \\
& \text { origin. }
\end{aligned}
$$


If it is assumed that the equilibrium concentration is established in the gas stream, the concentration of the precursor in the gas stream at the origin will be $\mathrm{N}_{c}$, and at $\mathrm{L}$, that is, upon the completion of one cycle but immediately before the beginning of the following cycle, it will be, based on Eq. (4.10), $\mathrm{N}_{\mathrm{C}} \mathrm{e}^{-\alpha_{\mathrm{O}} L}$. Hence, the reduction in the concentration upon the completion of one cycle is $\mathbb{N}_{c}\left(1-e^{-\alpha_{0} L}\right)$. For equilibrium, this reduction in concentration must be compensated by the addition of precursors from the source. The concentration of the precursors added to the stream by the source will be equal to the open-circuit concentration, $\mathbb{N}_{0}$. Equating the reduction in concentration to the amount added by the source gives

$$
N_{0}=N_{c}\left(1-e^{-\alpha_{0} L}\right)
$$

or

$$
N_{c}=\frac{N_{O}}{1-e^{-\alpha_{O} L}}
$$

where

$$
\alpha_{0}=\frac{I}{\bar{U}}\left(\lambda_{0}+\frac{4 P_{0} C_{0}}{d_{e}}\right) .
$$

It is apparent from Eq. (7.1) that the concentration will build up appreciably in the stream if the exponent $\left(\alpha_{0} I\right)$ is a very small quantity. Such is the case if the precursor does not deposit on the wall surface (i.e., $P_{0}=0$ ) and its decay constant is small. (i.e., long half-life) as compared with the time taken for the gas to make one complete recirculation (i.e., L/U). For instance, the concentration of the noble gas in the gas stream will increase because it does not deposit. The concentration of the larger sized particles will also build up with the time, since they deposit at a much lower rate than the smaller particles.

The closed-loop concentrations of the precursor at the origin would be almost the same as that for the open-10op concentration if particles deposit rapidly and their half-lives are small as compared with the time taken for one complete recirculation. In adusting the equations derived In the previous section to apply to closed loops, the open-circuit 
concentration, $\mathbb{N}_{0}$, in all the equations should be replaced by the closedloop concentration, $\mathrm{N}_{\mathrm{c}}$, as given by Eq. (7.I).

It is desirable to know the buildup of concentration in the gas stream for a closed loop as a function of the time. This can be evaluated from the solution of the time-dependent mass balance equation in the following manner.

The mass balance equation for the precursor in the gas stream is, based on Eq. (4.6),

$$
\frac{1}{U} \frac{\partial n_{0}(x, \theta)}{\partial \theta}=\frac{\partial n_{0}(x, \theta)}{\partial x}-\alpha_{0} n_{0}(x, \theta),
$$

where

$$
\alpha_{0}=\frac{1}{U}\left(\lambda_{0}+\frac{4 \mathrm{P}_{0} \mathrm{C}_{0}}{\alpha_{e}}\right) .
$$

Taking the Laplace transform of Eq. (7.3) and noting that $\mathrm{n}_{\mathrm{O}}(\mathrm{x}, \theta)=0$ gives

$$
\frac{1}{U} s \bar{n}_{0}(x)=-\frac{d \bar{n}_{0}(x)}{d x}-\alpha_{0} \bar{n}_{0}(x)
$$

where

$$
\begin{aligned}
s & =\text { Laplace transform variable, } \\
\bar{n}_{0}(x) & =\int_{0}^{\infty} e^{-s \theta} n_{0}(x, \theta) d \theta=\text { Laplace transform . }
\end{aligned}
$$

Rearranging Eq. (7.4),

$$
\frac{d \bar{n}_{0}(x)}{d x}+\left(\alpha_{0}+\frac{s}{U}\right) \bar{n}_{0}(x)=0
$$

The solution of $\mathrm{Eq} .(7.5)$ is

$$
\bar{n}_{0}(x)=\text { constant } x \exp \left[-\left(\alpha_{0}+\frac{s}{U}\right) x\right] \text {. }
$$

The unknown constant can be determined by considering the concentration at the source: 


$$
n_{0}(0, \theta)=N_{0}+n_{0}(L, \theta) \xi\left(\theta-\frac{L}{U}\right)
$$

where

$$
\begin{aligned}
L & =\text { total length of the loop, } \\
\xi\left(\theta-\frac{L}{U}\right) & =\text { unịt step function }=\left\{\begin{array}{l}
0 \text { when } \theta<\frac{L}{U} \\
1 \text { when } 0>\frac{L}{U}
\end{array} .\right.
\end{aligned}
$$

Taking the Laplace transform of Eq. (7.7),

$$
\bar{n}_{0}(0)=\frac{N_{0}}{S}+\mathcal{L} n_{0}(L, \theta) \xi\left(\theta-\frac{L}{U}\right) \text {, }
$$

where $\mathcal{L}$ denotes taking Laplace transform.

From Eqs. (7.6) and (7.8),

$$
\text { Constant }=\frac{N_{0}}{s}+\mathcal{L} n_{0}(L, \theta) \xi\left(\theta-\frac{L}{U}\right)
$$

Substituting Eq. (7.9) into (7.6),

$$
\bar{n}_{0}(x)=\left[N_{0} \frac{e^{-(x / U) s}}{s}+e^{-(x / U) s} \mathcal{L} n_{0}(L, \theta) \xi\left(\theta-\frac{L}{U}\right)\right] e^{-\alpha_{0} x} .
$$

Taking the inverse transform of Eq. (7.1.0),

$$
n_{0}(x, \theta)=\left[N_{0} \xi\left(\theta-\frac{x}{U}\right)+n_{0}(L, \theta) \xi\left(\theta-\frac{L}{U}-\frac{x}{U}\right)\right] e^{-\alpha_{0} x},
$$

where

$$
\xi\left(\theta-\frac{x}{U}\right)=\left\{\begin{array}{l}
0 \text { when } \theta<\frac{x}{U} \\
1 \text { when } \theta>\frac{x}{U}
\end{array}\right.
$$

and

$$
\xi\left(\theta-\frac{\mathrm{L}}{\mathrm{U}}-\frac{\mathrm{x}}{\mathrm{U}}\right)=\left\{\begin{array}{l}
0 \text { when } \theta<\frac{\mathrm{L}}{\mathrm{U}}+\frac{\mathrm{x}}{\mathrm{U}} \\
1 \text { when } \theta>\frac{\mathrm{L}}{\mathrm{U}}+\frac{\mathrm{x}}{\mathrm{U}}
\end{array} .\right.
$$

From Eq. (7.11) the source concentration can be evaluated as a function 
of the time, as follows:

$$
\begin{aligned}
& \text { Time, } \theta \quad \text { Source Concentration, } \mathrm{n}_{\mathrm{O}}(0, \theta) \\
& \mathrm{O}^{+} \quad \mathrm{N}_{\mathrm{O}} \\
& \left(\frac{L}{U}\right)^{+} \quad N_{O}+N_{O} e^{-\alpha_{0} I} \\
& \left(2 \frac{L}{U}\right)^{+} \quad N_{0}+N_{0} e^{-\alpha_{0} I}+N_{0} e^{-2 \alpha_{0} L} \\
& \left(i \frac{L}{U}\right)^{+} \quad N_{n} \sum_{j=0}^{i} e^{-j \alpha_{O} L}
\end{aligned}
$$

where $j=0,1,2, \ldots$, i.

For a large number of recirculations, the concentration in the gas stream at the origin approaches to the equilibrium source concentration for a closed loop given by Eq. (7.1):

$$
\mathrm{N}_{c}=\operatorname{Lim}_{i \rightarrow \infty} \mathrm{n}_{0}\left(0, i \frac{\mathrm{L}}{\mathrm{U}}\right)=\frac{\mathrm{N}_{O}}{1-\mathrm{e}^{-\alpha_{\mathrm{O}} \mathrm{L}}} .
$$

\section{EFFECTS OF TEMPERATURE GRADIE'NI' ON IEPOSITION RATE}

If fission products are deposited in a region where a temperature gradient exists in the gas stream normal to the wall surface, a thermal force acts on the particles down the temperature gradient and causes them to move away from the hot region. Depending on the direction of the temperature gradient, the rate of transport of particles from the gas stream to the wall surface is decreased or increased." Depositions due to concentration gradient and temperature gradient may be considered additive if no interaction is assumed between these two mechanisms.

The diffusion velocity for a binary mixture due to concentration and temperature gradients is given as ${ }^{5}$ 


$$
\text { Diffusion velocity }=-\frac{n_{t}^{2}}{n_{g}} D\left[\frac{d\left(\frac{n}{n t}\right)}{d y}+k_{t}-\frac{1}{T} \frac{d T}{d y}\right] \text {, }
$$

where

$$
\begin{aligned}
D & =\text { diffusion coefficient, } \mathrm{cm}^{2} / \mathrm{sec}, \\
n & =\text { concentration of fission products, particles } / \mathrm{cm}^{3}, \\
n_{g} & =\text { concentration of gas particles, particle } / \mathrm{cm}^{3}, \\
n_{t} & =\text { total concentration }=n+n_{g}, \text { particle } / \mathrm{cm}^{3}, \\
k_{t} & =\text { thermal-diffusion ratio, }\left(D_{\text {thermal }} / D\right), \text { dimensionless, } \\
y & =\text { radial distance from wall surface, } \mathrm{cm} .
\end{aligned}
$$

If the concentration of fission products in the gas stream is weak, that is, $\mathrm{n} \ll \mathrm{n}_{\mathrm{g}}$,

$$
\mathrm{n}_{\mathrm{t}}=\mathrm{n}+\mathrm{n}_{\mathrm{g}} \cong \mathrm{n}_{\mathrm{g}}
$$

Substituting Eq. (8.2) into Eq. (8.1) gives

$$
\text { Diffusion velocity }=-D\left(\begin{array}{l}
I d n \\
-\frac{d}{n}+k_{t} \frac{n_{t}}{n}-\frac{d T}{T} \frac{d y}{n}
\end{array}\right) \text {. }
$$

The thermal-diffusion ratio, $k_{t}$, can be expressed in terms of a thermaldiffusion factor, $\alpha_{t}$, $a s^{6}$

$$
k_{t}=\alpha_{t} \frac{n}{n_{t}} \frac{n_{g}}{n_{t}} \cong \alpha_{t} \frac{n}{n_{t}}
$$

if

$$
\mathrm{n} \ll \mathrm{n}_{\mathrm{g}}
$$

Substituting Eq. (8.4) into Eq. (8.3),

$$
\text { Diffusion velocity }=-D\left(\frac{1}{n} \frac{d n}{d y}+\alpha_{t} \frac{1}{T} \frac{d T}{d y}\right) .
$$

Since the mass flux is equal to the diffusion velocity times the particle concentration,

$$
\text { Mass flux }=-D\left(\frac{d n}{d y}+\alpha_{t} \frac{n}{T} \frac{d T}{d y}\right) \text {. }
$$


For turbulent flow the temperature and particle concentration in the turbulent core can be taken to be constant. A linear approximation can be assumed for the distribution of temperature and particle concentration in the laminar layer. Assuming zero wall concentration, the following relations can be written:

$$
\begin{gathered}
\frac{d n}{d y} \cong \frac{n_{\infty}}{\delta_{m}} \\
\frac{d T}{d y} \cong \frac{T_{\infty}-T_{W}}{\delta_{t}} \\
n \cong \frac{n_{m}}{2} \\
T \cong \frac{T_{\infty}+T_{W}}{2}
\end{gathered}
$$

Substituting Eq. (8.7) into Eq. (8.6) gives

$$
\text { Mass flux }=-D \frac{\mathrm{n}_{\infty}}{\delta_{m}}\left(I+\alpha_{t} \frac{\delta_{m}}{\delta_{t}} \frac{\mathrm{T}_{\infty}-\mathrm{T}_{\mathrm{w}}}{\mathrm{T}_{\infty}+\mathrm{T}_{\mathrm{w}}}\right) \text {. }
$$

The thickness of the mass boundary layer, $\delta_{m}$, from Eqs. (2.13) and (2.18) is

$$
\delta_{m} \cong \delta \mathrm{Sc}^{-1 / 3}\left(1+\frac{6}{7} \mathrm{Sc}^{1 / 3} \frac{\lambda \mathrm{x}}{\mathrm{u}_{\infty}}\right) \cong \delta \mathrm{Sc}^{-1 / 3},
$$

if $(6 / 7) \mathrm{Sc}^{1 / 3}\left(\lambda \mathrm{x} / \mathrm{u}_{\infty}\right) \ll 1$ [i.e., effects of radioactive decay on heatmass analogy are negligible if this condition is satisfied; see Eq.

$(2.24)]$. The thickness of the temperature boundary layer, $\delta_{t}$, by analogy is

$$
\delta_{t}=\delta \operatorname{Pr}^{-1 / 3}
$$

Substituting Eqs. (8.9) and (8.10) into Eq. (8.8) gives

$$
\text { Mass } f l u x=-D \frac{n_{\infty} S c^{1 / 3}}{\delta}\left[1+\alpha_{t}\left(\frac{P r}{S c}\right)^{1 / 3} \frac{T_{\infty}-T_{W}}{T_{\infty}+T_{W}}\right] \text {. }
$$


Note that the first term in the large brackets in Eq. (8.11) (i.e., unity) represents the component of the mass flux due to ordinary diffusion (i.e., random motion), and the second term is due to the temperature gradient (i.e., thermal diffusion). Hence the ratio of mass fluxes due to thermal diffusion to the fluxes due to ordinary diffusion becomes

$$
\frac{\text { Thermal diffusion mass flux }}{\text { Ordinary diffusion mass flux }}=\alpha_{t}\left(\frac{\mathrm{Pr}}{\mathrm{Sc}}\right)^{I / 3} \frac{\mathrm{T}_{\infty}-\mathrm{T}_{\mathrm{W}}}{\mathrm{T}_{\infty}+\mathrm{T}_{\mathrm{W}}} \text {. }
$$

By definition,

and

$$
\mathrm{T}_{l} \equiv \text { mean layer temperature }=\left(\mathrm{T}_{\infty}+\mathrm{T}_{\mathrm{W}}\right) / 2
$$

$$
\Delta \mathrm{T}=\text { temperature drop across the layer }=\mathrm{T}_{\infty}-\mathrm{T}_{\mathrm{W}} \text {. }
$$

Substituting the relations in Eq. (8.13) into Eq. (8.12) gives

$$
\frac{\text { Thermal diffusion mass flux }}{\text { Ordinary diffusion mass flux }}=\alpha_{t}\left(\frac{\operatorname{Pr}}{\mathrm{Sc}}\right)^{2 / 3} \frac{1 \Delta \mathrm{T}}{2} \frac{-}{2 \mathrm{~T}_{l}} \text {. }
$$

In Eq. (8.14), the values of $\alpha_{t}, \operatorname{Pr} / \mathrm{Sc}$, and $\Delta \mathrm{T} / \mathrm{T}_{l}$, for most practical cases, are less than unity, and the smaller these values are the less important becomes the thermal diffusion as compared with the ordinary diffusion.

\section{APPLICATION TO CORRELATION OF EXPERIMENTAL DATA}

Equations (4.13), (4.25), and (4.35) give the deposition on the wall surface of precursors and the first- and second-daughter products for fully developed flow in the regions away from the tube inlet. Equations (6.6) and (6.15) are for the deposition of the precursor and the first-daughter products in the region where the boundary layer is developing. These equations, however, are all for an open circuit. If the gas is recirculating, the open-circuit concentration of the precursor at the origin, $\mathrm{N}_{\mathrm{O}}$, in all those equations can be replaced by the closed-loop concentration, $\mathfrak{N}_{C}$, as given by Eq. (\%.11). The open-circuit concentration, 
$\mathrm{N}_{\mathrm{O}}$, can be calculated from Eq. (4.36) if the release rate of the source is known.

It is apparent from Eq. 4.13 that a plot of particle deposition at the wall surface against the distance along the tube on a semilog scale should give straight-line relations in the region away from the entrance effects, and the slope of this line is $-\alpha_{0}$. Therefore the value of the product $\mathrm{P}_{\mathrm{O}} \mathrm{C}_{\mathrm{O}}$ can be calculated from

$$
\alpha_{0}=\frac{1}{U}\left(\lambda_{0}+\frac{4 \mathrm{P}_{0} \mathrm{C}_{0}}{\mathrm{~d}_{e}}\right) \text {. }
$$

The value of $\mathrm{P}_{1} \mathrm{C}_{1}$ can be evaluated from Eq. (4.25) if the deposition of the first-daughter product at the wall surface is measured and the value of $\mathrm{P}_{\mathrm{O}} \mathrm{C}_{\mathrm{O}}$ is known. Equation (4.35) can be used to determine $\mathrm{P}_{2} \mathrm{C}_{2}$ for the second-daughter product. Evaluation of both $\mathrm{P}_{1} \mathrm{C}_{1}$ and $\mathrm{P}_{2} \mathrm{C}_{2}$ is more difficult than evaluation of $P_{O} C_{O}$ because of the complicated: form of the equations defining these quantities.

Once the value of PC is determined for a given fission-product species, a type of gas, and a particle size, the effects of coolant velocity and the passage equivalent diameter on PC can be established by substituting the explicit value of $C$, as obtained. from Eqs. (3.1) through (3.6) for the particular flow condition: of interest: For illustration: purposes; : fully developed turbulent flow in a circular tube is considered. The value of $C$ for this particular case is defined by the Eq. (3.6), that is, $\mathrm{c}=\mathrm{h}_{\mathrm{m}} ;$ therefore

$$
C=0.023 \frac{D^{0.7} \rho^{0.5} U^{0.8}}{\mu^{0.5} d^{0.2}}
$$

In the case of a perfect gas, the first approximation to the diffusion coefficient, D, for rigid elastic spheres, given by Chapman and Cowling,? can be expressed as:

$$
D=0.185 \times 10^{-2} \frac{\mathrm{T}^{3 / 2}}{\sigma^{2} \mathrm{p}}\left(\frac{1}{\mathrm{~m}}+\frac{1}{\mathrm{~m}^{\prime}}\right)^{2 / 2},
$$


where

$\sigma=$ distance between the centers of the two colliding spheres, A, $\mathrm{m}, \mathrm{m}^{\prime}=$ molecular weight of the colliding spheres,

$\mathrm{p}=$ pressure, atm,

$\mathrm{T}=$ temperature, ${ }^{\circ} \mathrm{K}$,

$\mathrm{D}=$ diffusion coefficient, $\mathrm{cm}^{2} / \mathrm{sec}$.

Hence,

$$
P C=C^{\prime} \frac{U^{0.8}}{d^{0.2}},
$$

where $C^{\prime}$ is a constant. Note that the constant $C^{\prime}$ is a function of the fission-product species, the type of gas, the probability of deposition, the temperature, and the pressure.

The unknown constant, $\mathrm{C}^{\prime}$, in Eq. (9.4), can be determined for a given fiscion product species, the type of gas, and the temperature and pressure level if the value of PC is determined experimentally in a manner described previously for a given gas velocity and the passage equivalent diameter.

Thus far the ideal case has been considered, that is, fission products or unitoim sizes. In practical applications, particles of a given fissionproduct species may be of various sizes. The present analysis may be applied for such cases by assuming that the value of PC determined for a given fission-product species represents a lumped value for the given species consisting of particles of various sizes. The shortcoming of this type of correlation is that the values of the constant $\mathrm{C}^{\prime}$ in Eq. (9.4) changes if the size spectrum of the particles changes. Furthermore, when a fission-product species consists of particles of various sizes, the smaller particles deposit at a much faster rate than the larger ones. This may alter the size spectrum of the particles with the distance and hence alter the value of $\mathrm{C}^{\prime}$.

It is to be noted that all the equations derived in thia analysis are for steady-state conditions. Equilibrium conditions must be established when correlating experimental data with the results from the equations given in this report. For stable or very long-lived fission-product species the concentration of the particles at the wall surface would be expected to bulla up for a long time. 


\section{SAMPLE CALCULATIONS}

Sample calculations were performed to estimate the deposition of particles from air streams at atmospheric pressure and temperature on the inside surface of a 0.8-cm-ID tube arranged in an open circuit. The concentration of particles in the gas stream was assumed to be uniform at the tube inlet, and laminar flow with $U=0.9 \mathrm{~cm} / \mathrm{sec}$ was considered. The result of these calculations for molecular iodine, with $\mathrm{D}=0.085 \mathrm{~cm}^{2} / \mathrm{sec}$, and for particles of larger sizes $(0.004 \mu)$, with $D=0.00294 \mathrm{~cm}^{2} / \mathrm{sec}$, are presented in Fig. 1. Equation (4.13) was used in conjunction with Eq. (3.4) in the region where there were no entrance effects, and Eq. (6.6) was used in conjunction with Eq. (3.3) where the entrance effects existed. Included on this figure are the data of Browning and Ackley ${ }^{8}$ for the same conditions as those for which the calculations were made. Their experimental data have been multiplied by a factor of 4 for normalizing. Good agreement between the experimental and the calculated data shows that the heat transfer analogy is applicable for correlating the diffusion data. It is interesting to note that Browning and Ackley ${ }^{8}$ correlated their data with the analytical solution of Gormley and Kennedy ${ }^{9}$ for diffusion from a gas stream in laminar flow through a cylindrical tube, and they obtained good correlations. Actually, the governing equation used for diffusion was $^{9}$

$$
\frac{\partial^{2} \psi}{\partial r^{2}}+\frac{1}{r} \frac{\partial \psi}{\partial r}-K_{1}\left(r_{w}^{2}-r^{2}\right) \frac{\partial \psi}{\partial x}=0,
$$

where

$$
\mathrm{K}_{I}=\frac{2 \mathrm{Q}}{\pi r_{\mathrm{W}}^{4} \mathrm{D}}
$$

whereas the mass transfer coefficient used in the present analysis was obtained by analogy from the solution of the classical Graetz equation for heat transfer in circular tubes under laminar flow conditions, 4, 10 that is,

$$
\frac{\partial^{2} \mathrm{~T}}{\partial r^{2}}+\frac{1}{r} \frac{\partial \mathrm{T}}{\partial r}-K_{2}\left(\mathrm{r}_{\mathrm{w}}^{2}-\mathrm{r}^{2}\right) \frac{\partial \mathrm{T}}{\partial \mathrm{x}}=0,
$$




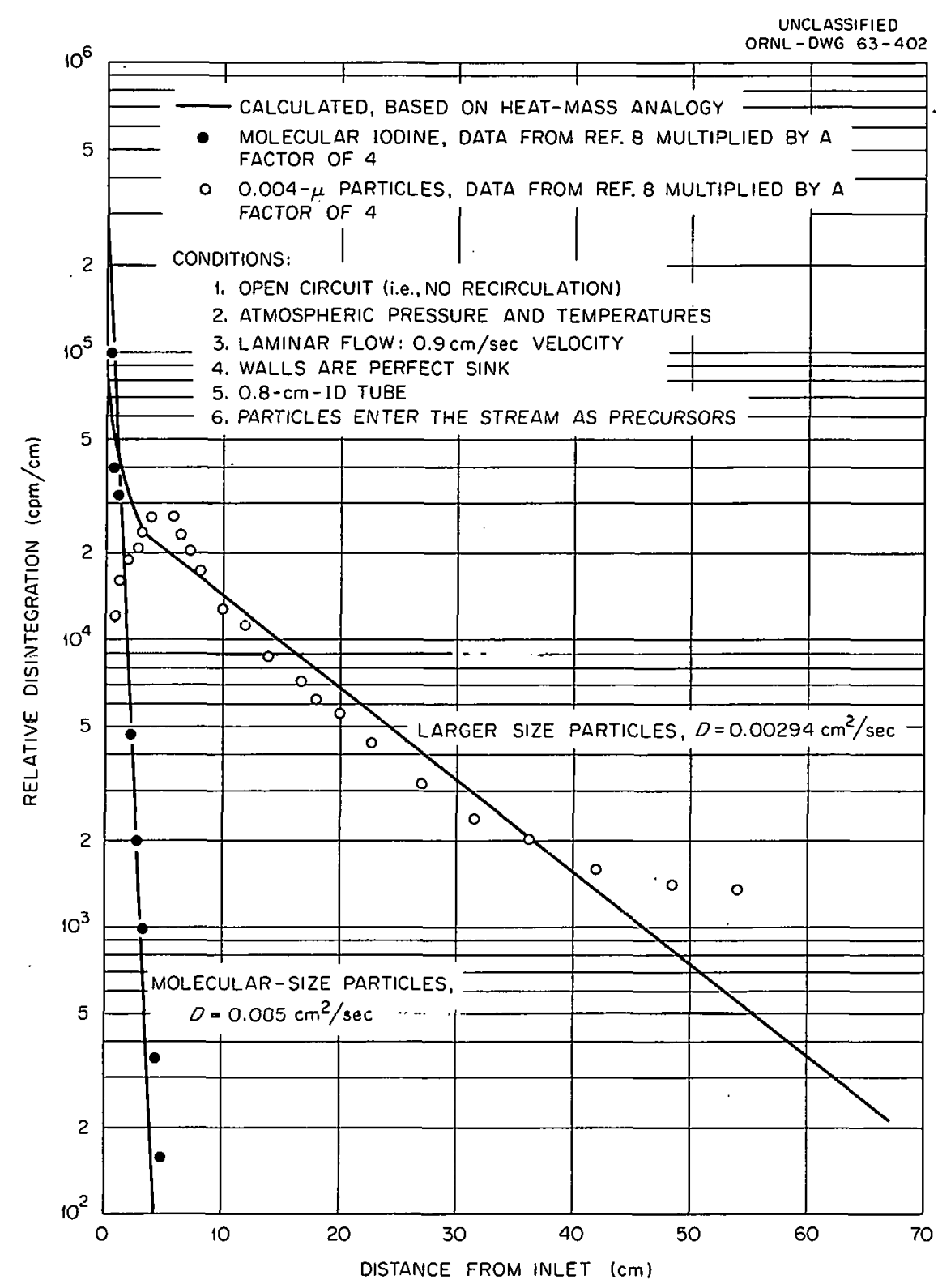

Fig. 1. Deposition of Particles from Air Streams in Laminar Flow.

where

$$
\mathrm{K}_{2}=\frac{2 \mathrm{Q}}{\pi \mathrm{r}_{\mathrm{W}}^{4}} \frac{\mathrm{C}_{\mathrm{p}} \rho}{\mathrm{k}}
$$

In both problems a fully developed parabolic velocity distribution was assumed. The boundary conditions were $\psi=0$ and $t=T_{W}=0$ at $r=r_{W}$, and $\psi=\psi_{0}$ and $T=T_{0}$ at the tube entrince. 
The calculated data in Fig. 2 show the effects of gas velocity on the deposition of molecular iodine and of larger particles entering the stream as precursors. Note that particles are carried far greater distances along the tube with higher gas velocities.

The data of Figs. 1 and 2 show that deposition is higher near the entrance if the gas velocities are low and the tube sizes are small. This

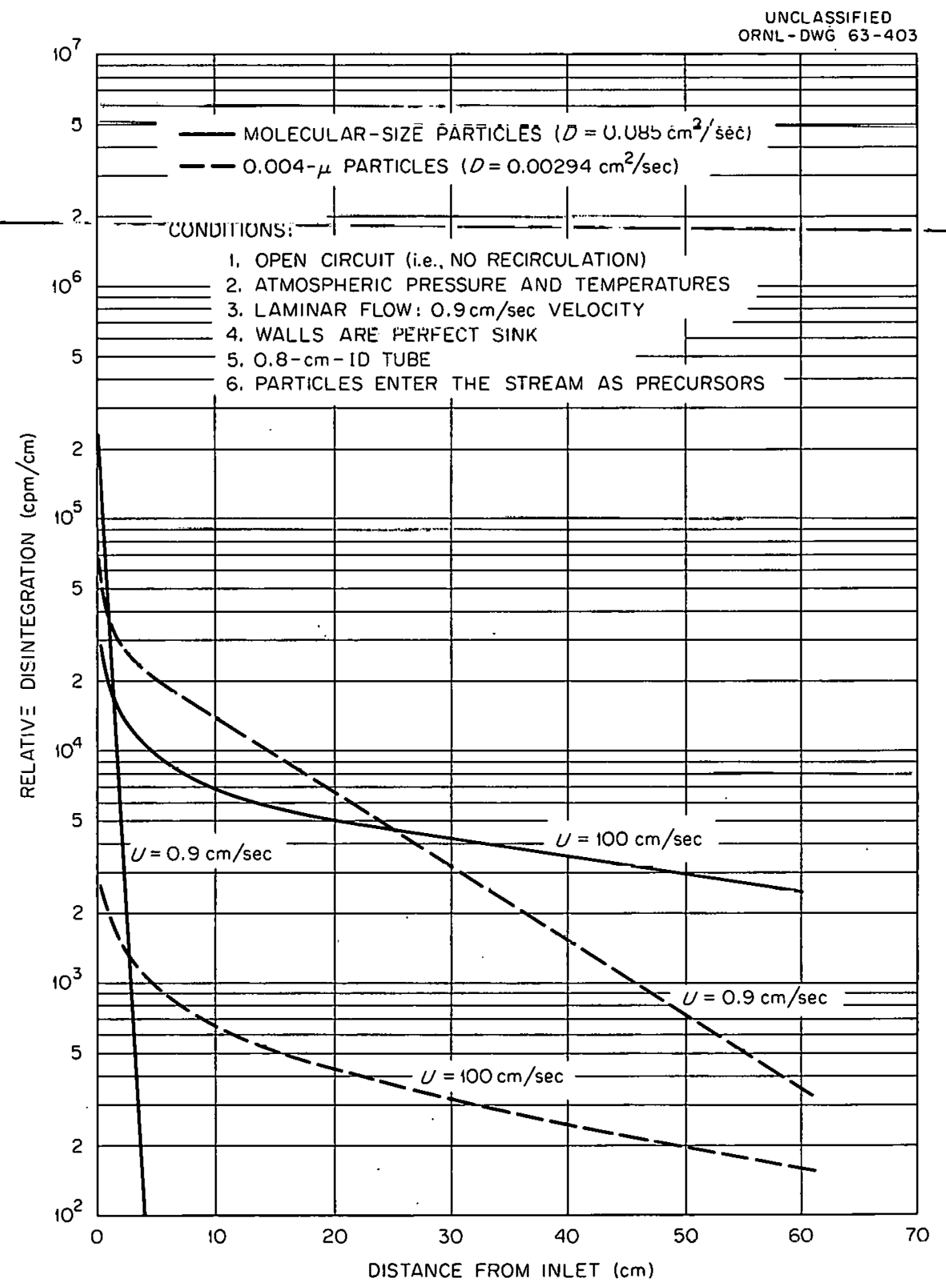

Fig. 2. Effects of Gas Velocity and Particle Size on Deposition Rate from Air Streams in Laminar Flow (Calculated). 
suggests that in removing molecular-size particles which enter the stream as precursors, filters would be more effective if they were placed near the source and in the location where the gas velocities are very low, such as the plenum chamber or inside the reactor core.

Test data obtained at Battelle Memorial Institute ${ }^{11}$ for the deposition of fission products from helium streams on the inside surface of a 0.37-in. -ID stainless steel tube are presented in Fig. 3. The data reproduced are for the portion of the loop where the temperature condition

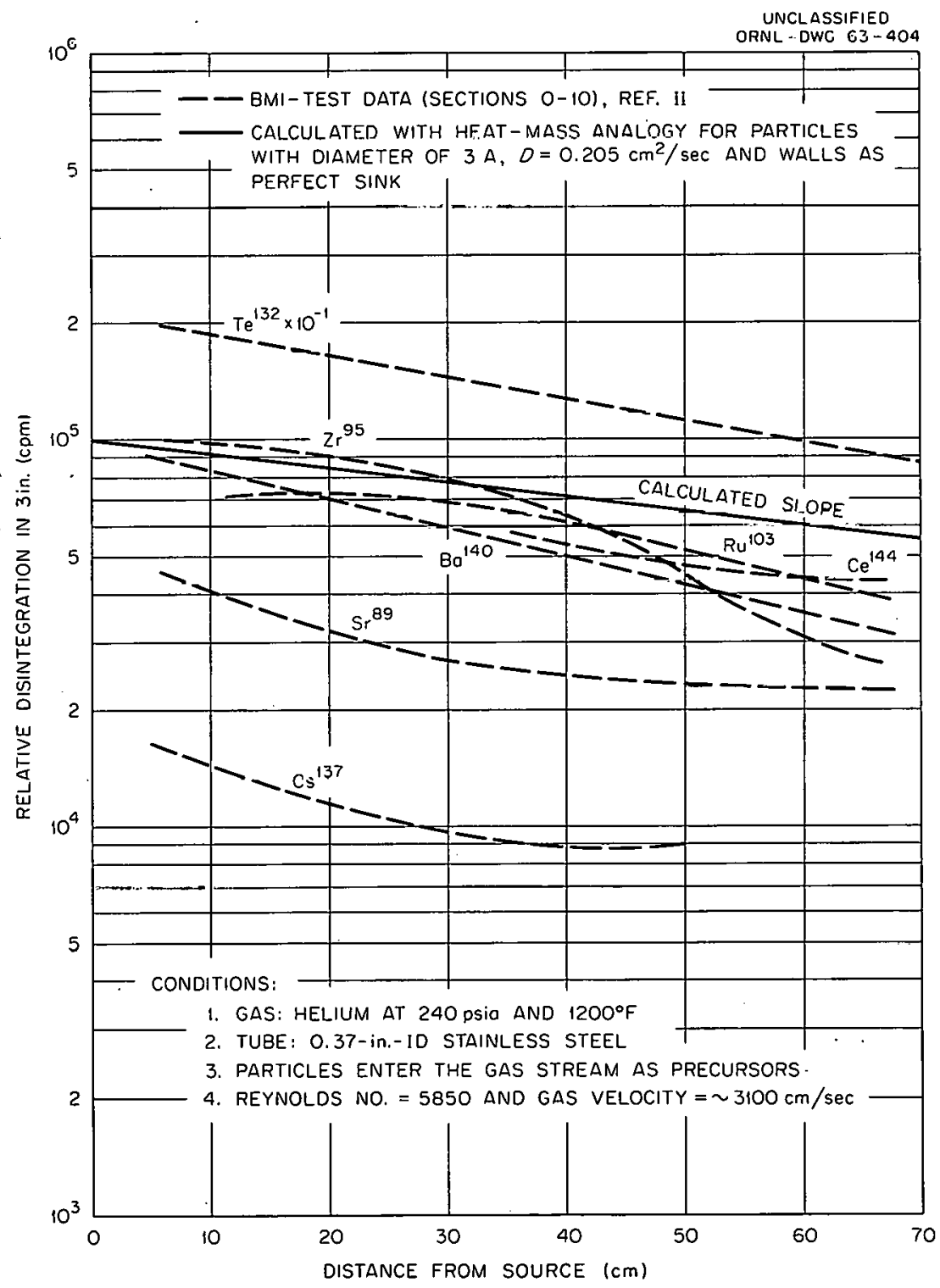

Fig. 3. Deposition of Fission Products from Gas Streams in Turbulent Flow. 
was considered to be isothermal, that is, a well-insulated portion. The gas temperature was $1200^{\circ} \mathrm{F}$ and the gas pressure 240 psia. The fission products entered the gas stream from an irradiated fuel specimen which was heated to $1800^{\circ} \mathrm{F}$ to allow fission products to diffuse into the gas stream. Fission products deposited on the wall surface were assumed to enter the gas stream as precursors, since the fuel specimen was stored after irradiation to allow the short-lived fission products to decay. The dotted lines on this figure are the experimental data, and the solid line was calculated from Eq. (4.13). Only the slopes of the curves are comparable, since the concentration of the particles in the gas stream at the origin was not known. The mass transfer coefficient was calculated from Eq. (3.6), since the flow was turbulent, and the diffusion coefficient was calculated from Eq. (9.3). The fission products were assumed to be of molecular sizes, with a mean diameter of $3 \mathrm{~A}$, and the wall surface was taken as a perfect sink (i.e., $P_{0}=1$ ). The resulting mean diffusion coefficient was $0.206 \mathrm{~cm}^{2} / \mathrm{sec}$. This value, and hence the slope of the calculated curve, would be slightly different if the exact molecular dimension for each species were considered separately. The slope of the calculated line appears to agree reasonably well with the slope of the experimental curves, suggesting that fission products existed in the gas stream in molecular sizes.

The test data from the same experiment but for the portion of the tube where the gas temperature was $430^{\circ} \mathrm{F}$ are presented in Fig. 4, and Fig. 5 shows the calculated values for the deposition of $\mathrm{Sr}^{89}$, assuming that it is produced in the gas stream as the second-daughter product from the decay of the $\mathrm{Kr}^{89}$ in the following manner:

$$
\mathrm{Kr}^{89}(3.18 \mathrm{~m}) \rightarrow \mathrm{Rb}^{89}(15.4 \mathrm{~m}) \rightarrow \mathrm{Sr}^{89}(54 \mathrm{~d})
$$

Air at atmospheric pressure and temperature was taken as the coolant gas. Molecular-size particles, a perfectly absorbing wall surface condition (i.e., $P=1$ ), and an open circuit (i.e., no recirculation) were assumed. The diffusion coefficient was taken as $\mathrm{D}=0.085 \mathrm{~cm}^{2} / \mathrm{sec}$. Deposition rates were calculated from Eq. (5.3) in conjunction with Eq. (3.4) for laminar flow and with Eq. (3.5) for turbulent flow. Note that the shape of the curves for the deposition of second-daughter products is different 


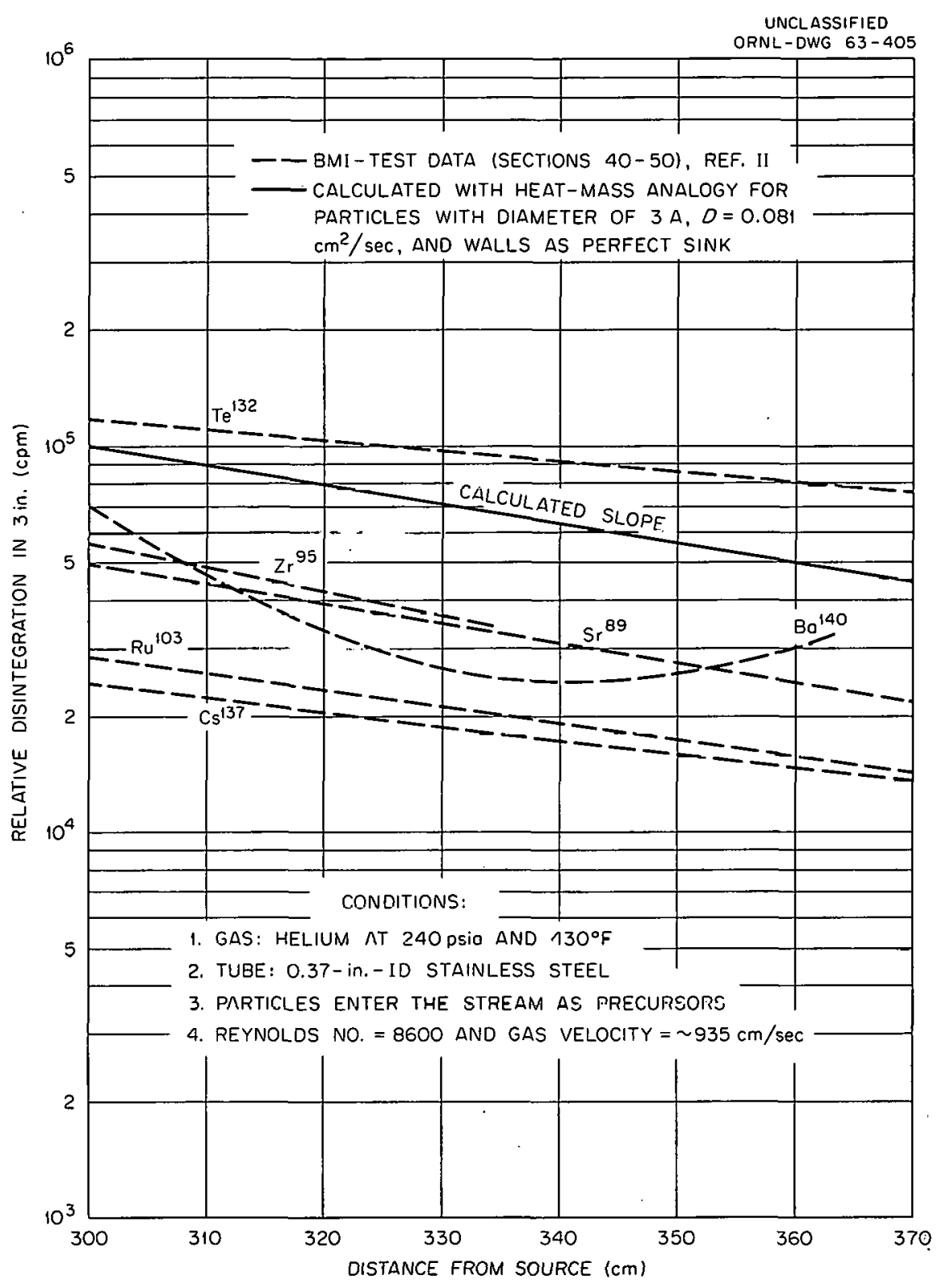

Fig. 4. Deposition of Fission Products from Gas Streams in Turbulent Flow.

from those shown in Figs. 1 through 4 for deposition of the precursor. Deposition first increases and then decreases in the case of particles appearing in the stream as the second-daughter product. The rate of deposition increases with lower gas velocities and smaller tube diameters, and the peak occurs at some distance downstream from the source. 


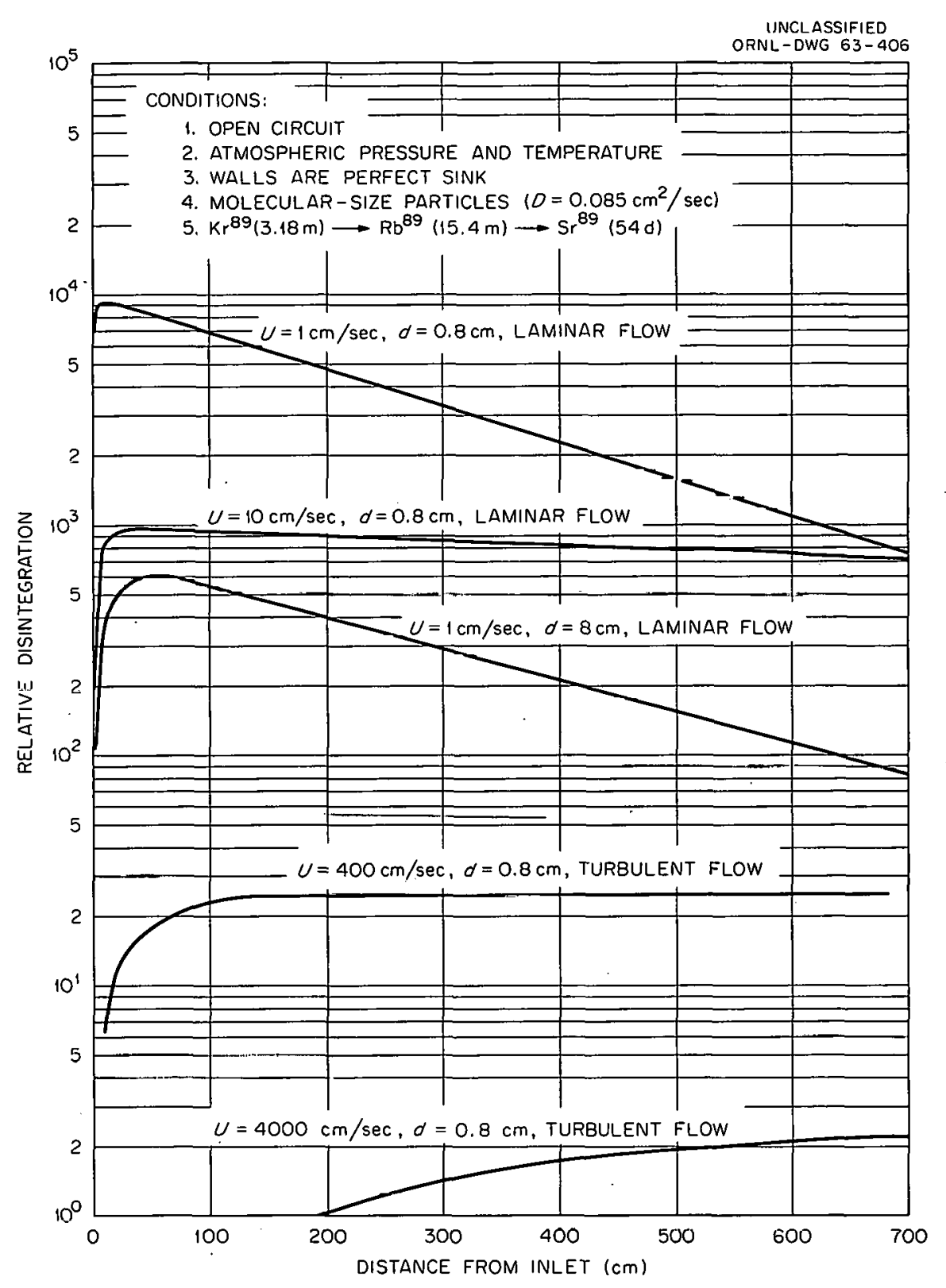

Fig. 5. Effects of Gas Velocity and Tube Diameter on Deposition of $\mathrm{Sr}^{89}$ Which Appears in Air Stream as Second Daughter Product of $\mathrm{Kr}^{89}$.

\section{ACKNOWLEDGEMENT}

The author gratefully acknowledges the valuable suggestions and criticism by R. N. Lyon and D. B. Trauger. 
REFERENCES

1. J. H. Perry, Chemical Engineering Handbook, p. 1020, Table 5 (1950).

2. H. Schlichting, Boundary Layer Theory, pp. 204, 256, Pergamon Press, New York, 1955.

3. R. N. Lyon, Remarks on Flow and Deposition of Radioisotopes in a Conduit, Oak Ridge National Laboratory, unpublished information, September 1962.

4. J. C. Knudsen and D. L. Katz, Fluid Dynamics and Heat Transfer, pp. 372, 394, 400, 482, 487, McGraw-Hill, New York, 1958.

5. S. Chapman and T. G. Cowling, The Mathematical Theory of Non-Uniform Gases, p. 244, Cambridge University Press, London, 1939.

6. Tbid., pp. 399, 417, Table 35.

7. Ibid., p. 250.

8. W. E. Browning, Jr., and R. D. Ackley, Characterization of Gas-Borne Radiodctive Materials by a Diffusion Cell Technique, "Reactor Chem. Div. Ann. Prog. Rcp. Jan. 31, 1962," USAEC Report ORNL-3262, Dak.Ridge National Laboratory.

9. G. P. Gormley and M. Kennedy, Diffusion from a Stream through a Cylindrical Tube, Proc. Royal Inst. Acad., 52A; 163-169 (1949).

10. M. Jakob, Heat Transfer, Vol. 1, p. 451, John Wiley \& Sons, New York, 1949.

11. G. E. Raines, Battelle Memorial Institute, personal communication to r. I. Neill, Oak Ridge National Laboratory. 


\section{THIS PAGE \\ WAS INTENTIONALLY \\ LEFT BLANK}


ORNL-3379

UC-80 - Reactor Technology

TID-4500 (20th ed., Rev.)

\section{Internal Distribution}

1. T. D. Anderson

2. S. H. Ball

3. C. D. Baumann

4. S. E Beall

5. J. C. Bresee

6. W. E. Browning

7. H. C. Claiborne

8. W. B. Cottrell

9. George E. Creek

10. D. R. Cuneo

11. F. W. Davis

12. I. T. Dudley

13. B. R. Fish

14. M. H. Fontana

15-19. A. P. Fraas

20. W. R. Gall

21. W. R. Grimes

22. H. W. Hoffman

23. R. W. Horton

24. G. W. Keilholtz

25. T. Kollzie

26. M. E. LaVerne

27. R. N. Lyon

28. H. G. MacPherson

29. A. P. Malmauskas

30. W. D. Manly

31. H. F. McDuffie

32. H. A. McLain
33. J. R. McWherter

34. W. R. Mixon

35. F. H. Neill

36. M. F. Osborne

37-46. M. N. Ozisik

47. L. F. Parsly, Jr.

48. B. F. Roberts

49. M. W. Rosenthal

50. G. Samuels

51. H. W. Savage

52. A. W. Savolainen

53. J. L. Scott

54. M. J. Skinner

55. D. B. Trauger

56. W. C. Waggerier

57. John L. Wantland

58. G. M. Watson

59. Herman Weeren

60. M. E. Whatley

61. R. P. Wichner

62. L. F. WoO

63-65. ORNL - Y-12 Technical Library Document Reference Section

66-68. Central Research Library

69-97. Laboratory Records Department

98. Laboratory Records Department, ORNL R.C.

\section{External Distribution}

99-101. W. F. Banks, Allis-Chalmers Mfg. Co.

102-104. P. D. Bush, Kaiser Engineers

105. R. A. Charpie, UCC Research Administration, New York, N.Y.

106. W. R. Cooper, Tennessee Valley Authority

107-108. David F. Cope, Reactur Division, AEC, ORO

109-110. R. W. Coyle, Vallecitos Atomic Laboratory

111. E. Creutz, General Atomic

112-114. R. B. Duffield, General Atomic

115. H. L. Falkenberry, Tennessee Valley Authority

116. D. H. Fax, Westinghouse Atomic Power Division 
117. M. Janes, National Carbon Research Laboratories, Cleveland, Ohio

118. T. Jarvis, Ford Instrument $\mathrm{Co}$.

119. James R. Johnson, Minnesota Mining and Manufacturing Company, Saint Paul, Minn.

120. Richard Kirkpatrick, AEC, Washington

121. C. W. Kuhlman, United Nuclear Corp.

122-123. H. Lichtenburger, General Nuclear Engineering Corp.

124. J. P. McGee, Bureau of Mines, Appalachian Experiment Station

125. R. W. McNamee, Manager, UCC Research Administration, New York, N.Y.

126. S. G. Nordlinger, AEC, Washington

127. R. E. Pahler, High-Temperature Reactor Branch, Reactor Division, AEC, Washington

128. H. B. Rahner, Savannah River Operations Office

120. Sorwin Rickard; General Atomic

130. M. 'L'. Simnari, Geirerer Atomic

131. Nathanial Stetson, Savannah River Operations Office

132. Donald Stewart, AEC, Washington

133. Philip L. Walker, Pennsylvaria State University

134. R. E. Watt, Los Alamos Scientific Laboratory

135-136. W. L. Webb, East Central Nuclear Group, Jnc.

13\%. C. E. Winters, UCC, Cleveland, Ohio

138. Lloyd R. Zumwalt, General Atomic

139. Division of Research and Development, AEC. ORO

140-752. Given distribution as shown in TID-4500 (20th ed., Rev.) under Reactor Technology category ( 75 copies - OTS) 